\title{
Prosthetic meshes for hernia repair: state of art, classification, antimicrobial approaches, and fabrication methods
}

\author{
Ángel Serrano-Aroca ${ }^{1} \&$ Salvador Pous-Serrano ${ }^{2}$ \\ ${ }^{1}$ Biomaterials and Bioengineering Lab, Centro de Investigación Traslacional San Alberto \\ Magno, Universidad Católica de Valencia San Vicente Mártir, c/Guillem de Castro 94, \\ 46001 Valencia, Valencia, Spain. \\ ${ }^{2}$ Surgical Unit of Abdominal Wall, Department of General and Digestive Surgery, La Fe \\ University Hospital, Spain.
}

\begin{abstract}
Worldwide, hernia repair represents one of the most frequent surgical procedures encompassing a global market valued at several billion dollars. This type of surgery usually requires the implantation of a mesh that needs the appropriate chemical, physical and biological properties for the type of repair. This review thus presents a description of the types of hernias, current hernia repair methods, and the state of the art of prosthetic meshes for hernia repair providing the most important meshes used in clinical practice by surgeons working in this area classified according to their biological or chemical nature, morphology and whether bioabsorbable or not. We emphasise the importance of surgical site infection in herniatology, how to deal with this microbial problem, and we go further into the future research lines on the production of advanced antimicrobial meshes to improve hernia repair and prevent microbial infections, including multidrug-resistant strains. A great deal of progress has been made in this biomedical field in the last decade. However, we are still far from an ideal antimicrobial mesh that can also provide excellent integration to the abdominal wall, mechanical performance, low visceral adhesion and minimal inflammatory or foreign body reactions, among many other problems.
\end{abstract}

Keywords: meshes, hernia, biomaterials, antimicrobials, surgery, abdominal wall 


\section{Contents}

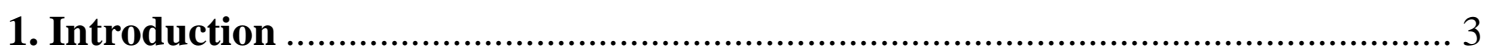

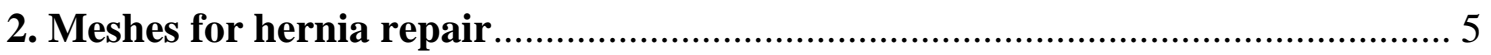

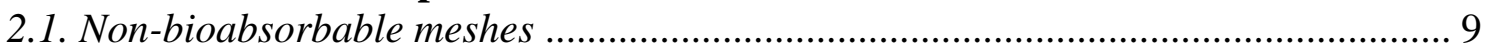

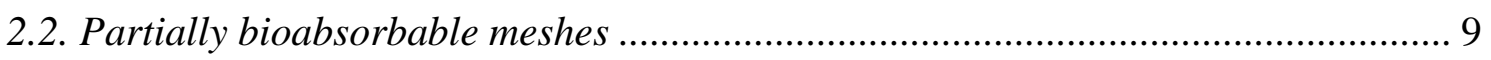

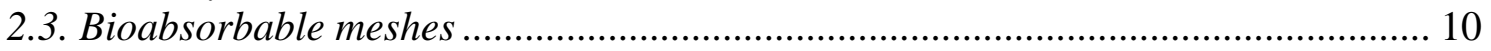

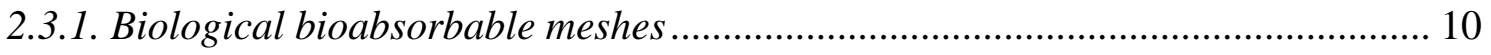

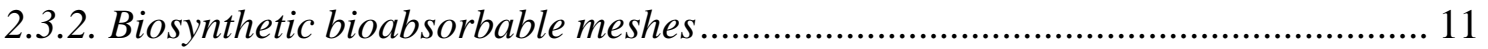

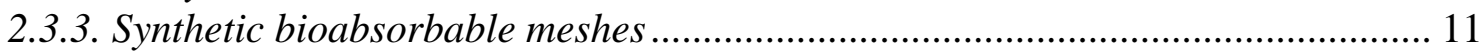

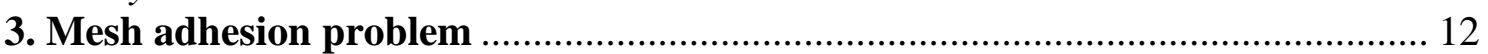

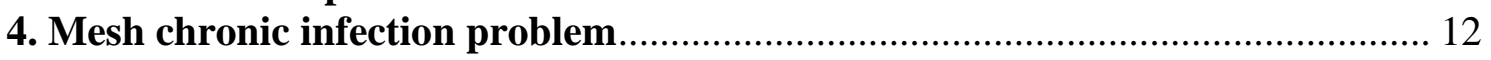

5. Antimicrobial meshes and their fabrication methods ........................................ 13

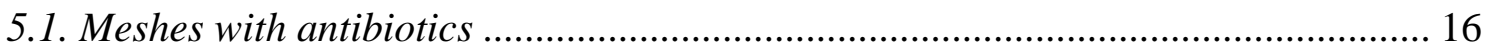

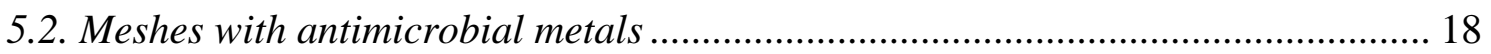

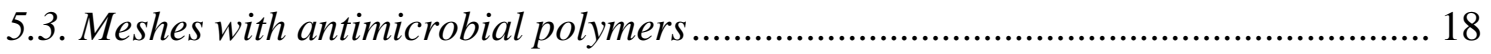

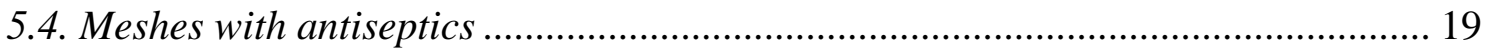

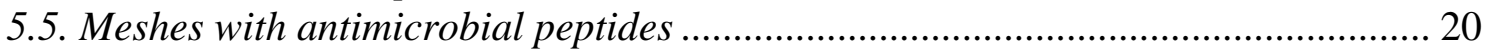

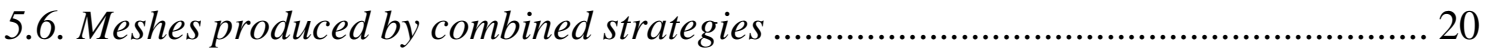

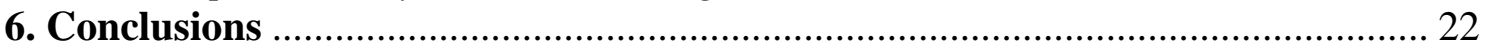




\section{Introduction}

Hernia repair is one of the most frequent surgical procedures with more than 20 million interventions per year worldwide [1,2]. In 2019, the global hernia repair market was valued at $\$ 4.75$ billion, and it is estimated to rise to $\$ 6.3$ billion by 2027 [3]. Hernias of the abdominal wall are classified into primary hernias (inguinal, femoral, umbilical, epigastric, Spiegel and lumbar) and secondary or incisional hernias, which are produced after incision of the abdominal wall [4]. Ventral hernia is an inclusive term for incisional, umbilical, epigastric, Spiegel and lumbar hernias, that is, those that are not inguinal nor femoral hernias [5]. Hernias are mainly formed due to obesity, other co-morbidities, wound infections, immunosuppression, and prostatism [5-7]. After abdominal surgery, incisional hernia presents an incidence ranging from 11 to $20 \%$ [8-10]. Surgeries performed for inguinal hernia repair is among the most common interventions [11-13] in both adults and children [14-16]. Inguinal hernias are usually symptomatic and their only cure is surgery [1]. However, even a watchful waiting approach in the asymptomatic group results in surgery in most cases [17]. Prior to the use of prosthetic meshes for inguinal hernia repair, suture repair methods, such as Bassini's, were the most common techniques employed in this type of intervention $[18,19]$. However, improvements in the surgical technique [20,21], along with the development of new advanced biomaterials have made prosthetic meshes important in hernia repair [22]. These meshes render easier closure, tension-free, and ensure high wound strength [23]. The main inguinal hernia repair methods include the Lichtenstein onlay patch, the Plug and patch method, Kugel's technique and the Laparoscopic approach [24]. The Lichtenstein tension-free repair is considered the gold standard [25]. This method approaches the inguinal canal [25] and reinforces the floor with a piece of flat prosthetic mesh [24]. The plug and patch method (Rutkow-Robbins technique and other similar methods) involves placing a prosthetic mesh plug through the defect in the inguinal canal [24]. Complications are rare; however, there is a possibility of patient discomfort, given the geometry of the plug [26]. This method is more expensive than the Lichtenstein technique [27]. The international guide to the management of inguinal hernia (HerniaSurge) recommends not using the plug because it adds a high amount of prosthetic biomaterial, it is necessary to enter the anterior and posterior plane and the additional cost [1]. Kugel's technique [28] uses a bilayer patch placed in the preperitoneal area and has achieved a recurrence rate of $0.4 \%$ [29]. The laparoscopic approach includes two different techniques: total extraperitoneal (TEP) and transabdominal preperitoneal (TAPP) repairs [30]. Both TAPP and TEP techniques obtain similar results [1]. The laparoscopic approaches for hernia repair cost more and take longer [31] and can produce several complications such as intestine, bladder and vascular injury or nerve entrapment [32]. However, laparoscopic methods show a faster recovery and present a low risk of chronic postoperative pain [1].

The laparoscopic technique has been well accepted for the treatment of incisional hernia but the ideal mesh produced with the ideal biomaterials has not yet been found [33]. There is consensus on its indication in bilateral inguinal hernias, recurrent hernias of the anterior pathway or in women, but although this type of approach is also recommended, due to the advantages described above, in unilateral male hernias its implementation has not been generalized in routine clinical practice [1]. The repair of primary umbilical or epigastric hernias involves the placement of preperitoneal prosthetic materials except if the size of the hernial defect is small $(0-1 \mathrm{~cm})$ [34]. Hernias classified as incisional and parastomal usually require the placement of one or more prostheses since otherwise the recurrence rate is very high. The site of the placement of this prosthesis (onlay, sublay, etc.) is variable according to the characteristics of the incision, location, 
type, size, preferences of the surgeon, etc. Complex incisional hernias may require abdominal preparation before surgery with infiltration of botulinum toxin and sometimes also with the creation of a progressive pneumoperitoneum [35,36].

Hernia repair is thus characterized by the increasing use of prosthetic meshes made of pure or different hybrid biomaterials, depending on the type of surgery [37]. Figure 1 provides an example of a large incisional hernia which required the use a polyvinylidene difluoride (PVDF) prosthetic mesh.
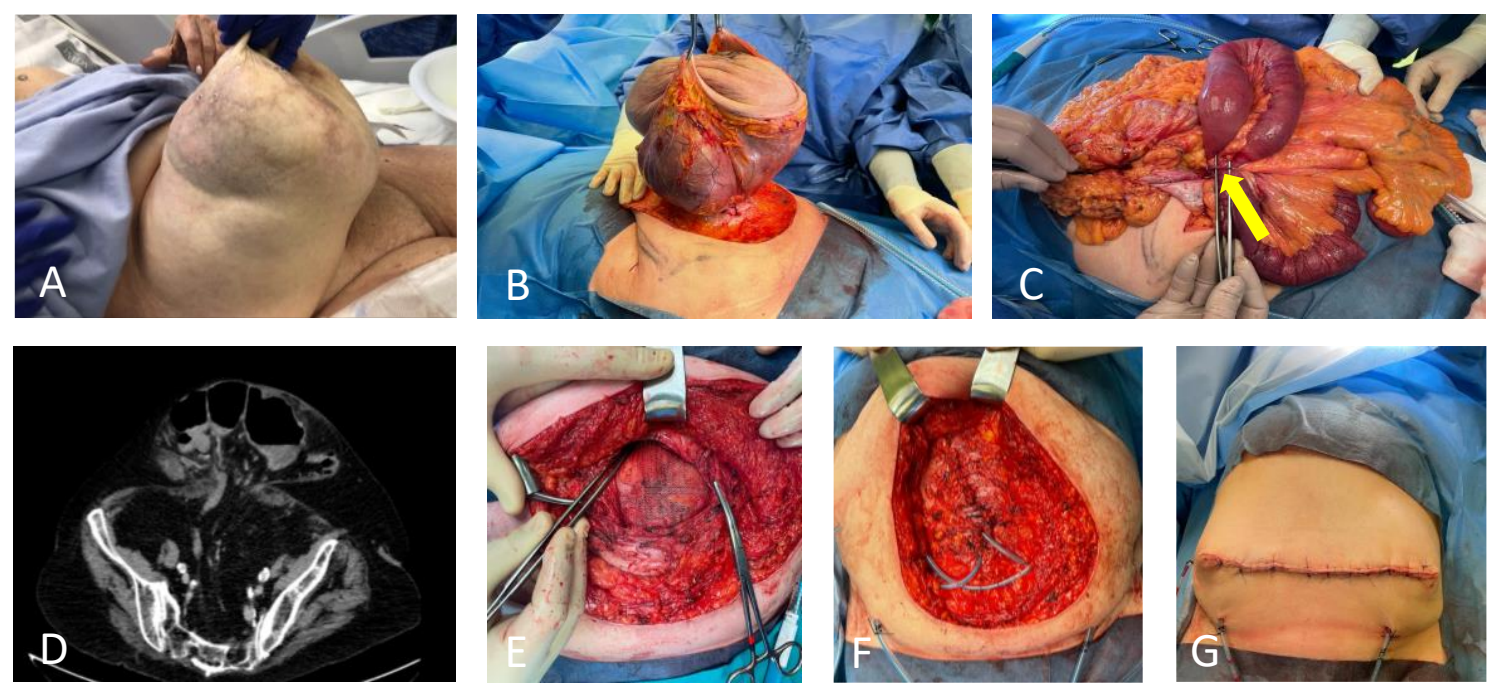

Figure 1. Example of large incisional hernia (A). Hernia M3M4W2according to the classification of the European Hernia Society [4] (22x9.7x25 cm transversal x anteroposterior x craniocaudal) with an $8 \times 12$ $\mathrm{cm}$ hernial defect (transverse $\mathrm{x}$ craniocaudal) that produces obstruction in handle closed by fibrous bands (yellow arrow in C) (B \& C). Image of the hernial defect in axial tomography section (D). Wall repair with placement of a retromuscular PVDF prosthesis and final result (E, F and G).

After the insertion of a foreign material into the human body, such as a prosthetic mesh, the immune system produces a reaction whose intensity and chronicity depend on the chemical nature and morphology of the mesh [38], so that serious problems such as shrinkage, seroma, erosion, encapsulation, and pain can occur [39]. In fact, common biomaterials, such as polypropylene (PP), have been broadly used in clinics due to their good biocompatibility and may trigger a cascade of histopathological mechanisms and immune reactions in the patient in the long term. The level of inflammatory cytokines and pro-angiogenic factors depends on the nature of the implanted meshes (biological or synthetic) [40]. A method of avoiding the post-implantation inflammatory response is to load the meshes with various anti-inflammatory drugs such as cortisone [41], ibuprofen $[42,43]$, or tetracycline $[44,45]$. For example, local cortisone release was found to limit the inflammatory reaction, reduce the size of the granuloma, and improve neovascularization. Insertion of a medical device is known to increase the susceptibility to infection 10,000 to 100,000 times [46], and bacterial contamination has been reported in a high percentage of the total implanted prosthetic meshes during surgery and after years of implantation [47,48]. Some authors have used mesh prophylaxis before the operation and reported a significant reduction of mesh infection [49]. For example, gentamicin was able to reduce mesh infections [50]. Another alternative antibacterial strategy consists of antibiotic prophylaxis for open mesh repair in high-risk patients and low-risk settings [1]. However, the current international guidelines do not recommend antibiotic prophylaxis in open surgery for medium-risk patients in low-risk settings [1], and it is not recommended in any case of laparoscopic repair. In high-risk settings, however, it is recommended in all cases except laparoscopic interventions. In this regard, 
the development of antimicrobial meshes, or meshes made with biomaterials able to impede microbial infections is gaining importance in the field of hernia repair [51]. Due to the inappropriate use of antibiotics, bacterial resistance levels have increased and become a serious health problem that could produce more deaths than cancer by the year 2050, according to the World Health Organization [52]. The next generation of prosthetic meshes therefore must be engineered with biomaterials able to impede infection, including those that are multidrug-resistant.

\section{Meshes for hernia repair}

Open non-mesh herniorrhaphy has been successfully performed by surgeons for many decades. However, the surgeon's experience played a very important role in the recurrence rate, which varies considerably. The introduction of meshes for hernia repair achieved tension-free hernioplasties and provided a new solution to produce relatively similar results that do not depend on the surgeon [53]. For this reason, several clinical trials have been carried out to find the optimal prosthetic mesh [54-56] and the best technique for implantation[57,58]. In this regard, biocompatibility and mesh-related complication issues such as pain, seroma and persisting infection (chronic infection or biofilm) are the most important factors [59]. According to the experience of the authors of this review, the ideal or perfect mesh would be made of a material that achieves good integration with the abdominal wall and possesses wide pores, low density, high elasticity, mechanical functionality, low incidence of visceral adhesions, good resistance to infection in contaminated areas, and minimal inflammatory or foreign body reaction. From the currently available meshes, the PP mesh fulfils all these requirements with the exception that it fails in the incidence of visceral adhesions because it is not possible to place the mesh in contact with the viscera. Furthermore, the PP mesh does not involve antimicrobial activity and usually requires the addition of antibiotics, silver ions or alternative antimicrobial approaches. However, the increasing microbial resistance to antibiotics [52] and metals such as silver ions [60] is demanding the development of new alternative antimicrobial meshes that could provide long-lasting solutions. Several classifications of meshes for hernia repair have been proposed so far. The first classification defined four types of prostheses mainly according to the porosity and chemical nature of the materials employed in their production [61]. A classification was reported according to physical and biological properties such as porous and non-porous, pore size, 3D morphology, biological origin, and additional features [62]. However, here we provide an updated classification of meshes based on Bellón's classification [63] showing the most frequently employed meshes in clinical practice and considering the chemical nature of their materials, application site, biodegradability and biological origin (see Table 1). 


\begin{tabular}{|c|c|c|c|c|}
\hline MESH TYPE & MESH SUBTYPE & BIOMATERIAL TRADEMARK & INTEGRATION & NEOPERITONEUM \\
\hline \multirow{8}{*}{$\begin{array}{l}\text { NON- } \\
\text { BIOABSORBIBLE }\end{array}$} & \multirow{6}{*}{ RETICULAR } & POLYPROPYLENE (PP) Optilene® Prolene $₫$ Herniamesh $₫$ & $* * * * *$ & * \\
\hline & & POLYESTER (PE) Parietex® & $* * * * *$ & $*$ \\
\hline & & POLYTETRAFLUOROETYLENE (cPTFE) Infinit@ PTFE mesh & $* * * *$ & * \\
\hline & & POLYVINYLIDENE FLUORIDE (PVDF) Dynamesh® & $* * * *$ & * \\
\hline & & PP + TITANIUM TiMesh $®$ & $* * * *$ & $* * *$ \\
\hline & & PP WITH SILVER IONS Optilene Siver Mesh ® & $* * * * *$ & * \\
\hline & LAMINAR & ePTFE (EXPANDED) Gore-Tex® DualMesh ${ }^{\circledR}$ & $* *$ & $* * * * *$ \\
\hline & HYBRID & $\begin{array}{l}\text { PP/ePTFE Ventralex тм Hernia Patch } \\
\text { PP/PVDF Dynamesh@IPOM }\end{array}$ & $\begin{array}{l}* * * * * \\
* * * * *\end{array}$ & $\begin{array}{l}* * * * * \\
* * * * * *\end{array}$ \\
\hline \multirow{8}{*}{\begin{tabular}{|l} 
PARTIALLY \\
BIOABSORBABLE
\end{tabular}} & \multirow{5}{*}{ COMPOSITE } & PP/POLIGLECAPRONE-25 UltraproTM & $* * * * *$ & $* * * * *$ \\
\hline & & PP/POLIDIOXANONE/OXIDATED REGENERATED CELULLOSE ProceedTM Ventral Patch & $* * * * *$ & $* * * * *$ \\
\hline & & PP/HYALURONIC ACID+CARBOXYMETHYLCELLULOSE+ POLYETYLENE GLYCOL Sepramesh ® & $* * * * *$ & $* * * * *$ \\
\hline & & PP/ o Sepra® Hydrogel Barrier Ventralex ST® Ventrio ST ® Ventralight ST® & $* * * * *$ & $* * * * *$ \\
\hline & & POLYGLYCOLIC ACID (PGA)+ POLY(TRIMETHYLENE CARBONATE) (PTMC)/PTFE/PGA+PTMC Gore® Synecor & $* * * * *$ & $* * * * *$ \\
\hline & \multirow{3}{*}{\begin{tabular}{|l|} 
AUTOADHESIVE \\
COMPOSITE
\end{tabular}} & PP/POLYETHYLENE GLYCOL+POLYVINYLPYRROLIDONE Adhesix® & $* * * * *$ & * \\
\hline & & PP/POLILACTIC ACID Parietene ${ }^{\mathrm{TM}}$ ProGrip ${ }^{\mathrm{TM}}$ & ****** & $*$ \\
\hline & & PE/POLILACTIC ACID Parietex ${ }^{\mathrm{TM}}$ ProGrip TM & $* * * * *$ & * \\
\hline \multirow{8}{*}{ BIOABSORBIBLE } & \multirow{4}{*}{ BIOLOGICAL } & PORCINE DERMIS Permacol ${ }^{\mathrm{TM}}$ Strattice $^{\mathrm{TM}}$ & $* *$ & $* * * * *$ \\
\hline & & PORCINE INTESTINAL SUBMUCOSE Surgisis® & $* *$ & $* * * * *$ \\
\hline & & BOVINE PERICARDIUM Veritas® & $* *$ & $* * * * *$ \\
\hline & & HUMAN DERMIS Alloderm $®$ FlexHD® AlloMax ${ }^{\mathrm{TM}}$ & $* *$ & $* * * * * *$ \\
\hline & BIOSYNTHETIC & BACTERIAL POLYMER MESHES (P4HB) Phasix TM and Phasix ${ }^{\mathrm{TM}}$ ST (o Sepra® Hydrogel Barrier) & $* * * * *$ & $* \& * * * * *$ \\
\hline & \multirow{3}{*}{ SYNTHETIC } & POLYGLACTIN 910 Vicryl TM & $* * * * *$ & $* * *$ \\
\hline & & PGA + PTMC Gore $®$ BIO-A® & $* * * *$ & $* * * *$ \\
\hline & & POLYLACTIC ACID + PGA + PTMC TIGR - matrix ${ }^{\circledR}$ & $* * * *$ & $* * * *$ \\
\hline
\end{tabular}

Table 1. Classification of prosthetic meshes for hernia repair most used in clinical practice. Sepra ${ }^{\circledR}$ Hydrogel Barrier: Sodium hyaluronate hydrogel, carboxymethylcellulose and polyethylene glycol. Bonded to polypropylene by polyglycolic acid fibres. Trademarks most used in clinical practice are indicated in blue letters. The meshes that allow intraperitoneal placement are highlighted in green. The mesh tissue integration and capacity to create neoperitoneum is indicated (ranging from excellent $* * * * *$ to very poor $*$ ) 
This new classification was designed with the goal of being useful to surgeons when deciding the type of mesh to be used in different interventions. The abundant number of biomaterials available for abdominal wall repair calls for a practical classification that attempts to answer the questions that a surgeon may ask himself when using them. The first important question is to know if the prosthesis is permanent and if it will be partially or completely absorbed. The second question consists of knowing whether the type of mesh is reticular, laminar, or composite. The last, but not the least, question is to know whether the mesh can be placed intra-abdominally. Integration is related to the capacity of the mesh to allow the growth of cells between its fibres so that the reticular usually allow better integration than the laminar types [64]. Connective tissue surrounds the filaments, forming spirals over them, and there is a major angiogenesis [65]. Lamellar prostheses are mainly represented by expanded PTFE (ePTFE) and their integration is cellular, the cells from the tissue receptor invading the outermost thirds of the material. The vessels do not penetrate the interstices of the ePTFE, and the prosthesisreceptor tissue interface is weak from a mechanical point of view [66]. The integration of the mesh also correlates with the mechanical resistance (the greater the integration, the greater the resistance) [67]. Regarding the neoperitoneum formation capacity, the structure of a biomaterial influences this behaviour rather than its chemical composition [68]. Lamellar prostheses allow a good development of the neoperitoneum. In experimental studies an early network of collagen fibres has already been observed covered with typical mesothelial cells [64]. These fibres are placed parallel to the prosthetic surface and are accompanied by a large number of cells, especially fibroblasts and some foreign body reaction cells. After this time, the neoperitoneum is remodelled, and most cells that react to foreign bodies disappear (index of good tolerance of the prosthesis), and fibroblasts are the dominant ones. The collagen fibres are parallel to the prosthetic surface and the mesothelium is outside these, in contact with the visceral peritoneum. The genesis of this perfectly shaped neoperitoneum avoids the formation of adhesions, which is one of the complications that can appear after the placement of a prosthesis in contact with the visceral peritoneum. On the other hand, as PP-type reticular prostheses generate a neoperitoneum with a disorganized structure, rough in texture, with some areas of hemorrhage and necrosis that facilitate adhesions [69], the reticular structure of the prosthesis probably conditions an inappropriate arrangement of the mesothelial cells on it.

For all these reasons, we present here a classification of the most important meshes used in clinical practice with all their information regarding biomaterials, trademarks, tissue integration and capacity to create neoperitoneum (Table 1). The manufacturing materials of 3D prostheses with special designs for specific situations such as meshes designed for laparoscopic repair of inguinal hernias are also included in this table.

The pore size of the most common biomaterials used for hernia surgery can range from very large ( $>2000 \mu \mathrm{m})$ to micropores $(<100 \mu \mathrm{m})$ [70]. Larger pores render it easier to increase vascularization, enhance wound healing, among the many other required properties for hernia repair [71-73]. However, the problem of using meshes with large pores is the increased risk of adhesion to internal viscera $[61,74]$. The weight $\left(\mathrm{in} \mathrm{g} / \mathrm{m}^{2}\right)$ is another parameter usually employed to classify meshes from heavyweight $(<90)$ to ultra-lightweight $(<35)$ [70]. High weight meshes are associated with chronic pain from profound foreign body response and fibrosis, among other complications $[71,75]$. Therefore, it is important to reduce the weight of meshes, while retaining the mechanical resistance required for abdominal wall repair [60,61]. Mono-filaments are the most frequent mesh morphology used for inguinal hernia [76], or several braided fibres such as multi-filaments by polymer extrusion [77]. The filament structure affects several properties of the prosthetic mesh such as molecular permeability, pliability and mechanical performance [76]. Multifilament meshes are commonly associated with a higher risk of infection due to the interstices formed between the braided fibres [39,76]. However, new multifilament meshes have been developed with partially biodegradable filaments that provide enhanced physical and biological properties [37]. The manufacturing process (knitted, foil, woven, non-woven, etc.) also affects their properties [78]. Some techniques used in the production of porous polymers like scaffolds include polymerization using solvents [79-83], the porogen technique [84-86], electrospinning [87-89], and 3D printing [90-92], among others. Table 2 provides several examples of the wide range of pore sizes, weights, and morphology available in the market for the same and different types of meshes. 
Table 2. Examples of prosthetic meshes with different pore size, weight, and morphology.

\begin{tabular}{|c|c|c|c|}
\hline Biomaterials Trademark/Manufacturer & Pore size & Weight $\left(\mathrm{g} / \mathrm{m}^{2}\right)$ & Morphology \\
\hline PP (Optilene) Optilene ${ }^{\circledR}$ & $1.0 \mathrm{~mm}[93]-2.8[94]$ & $36[93,95]-48[96]$ & Monofilament[97] \\
\hline PVDF Dynamesh® & $1.1-1.3 \mathrm{~mm} \mathrm{[98]}$ & $45-73$ [99] & Monofilament [98] \\
\hline PP/PVDF Dynamesh®IPOM & $0.6 \mathrm{~mm}[94]$ & $60[94]-108[100]$ & Two-layered mesh [100] \\
\hline PP coated with plasma Ti TiMesh ${ }^{\circledR}$ & $>1 \mathrm{~mm}[103]$ & $16 / 35 / 65[103]$ & Monofilament [103] \\
\hline PP coated with $\mathrm{TiO}_{2} \mathrm{TiO}_{2} \mathrm{Mesh}{ }^{\circledR}$ & $3 \mathrm{~mm}[103]$ & 45 [103] & Monofilament [103] \\
\hline ePTFE Gore-Tex $\AA$ DualMesh $®$ & $0.003-0.022 \mu \mathrm{m}[104]$ & $320[105]$ & Foil[106] \\
\hline PP/PLA Parietene ${ }^{\mathrm{TM}}$ ProGrip ${ }^{\mathrm{TM}}$ & $1.1-1.7 \mathrm{~mm} \mathrm{[108]}$ & $41[108]$ & Monofilament [108] \\
\hline Polyester/PLA Parietex ${ }^{\mathrm{TM}}$ ProGrip ${ }^{\mathrm{TM}}$ & $1.5 \mathrm{~mm}[109]$ & 38 [109] & Knitted [109] \\
\hline Silk fiber-based meshes Allergan & $1 \mathrm{~mm}^{2}[110]$ & $50[111]$ & Multifilament [111](woven) [110] \\
\hline Bacterial polymer meshes (P4HB)Phasix ${ }^{\mathrm{TM}}$ & $0.258 \mathrm{~mm}^{2}[112]$ & $182[112]$ & Monofilament (knitted)[112] \\
\hline PLGA-based meshesVicryl Rapide ${ }^{\mathrm{TM}}($ Polyglactin 910$)$ & $0.5 \mathrm{~mm}[107]$ & $50[107]$ & Multifilament (woven or knitted)[107] \\
\hline PLA-based meshes Ethicon & $0.2-1.4 \mathrm{~mm}[113]$ & $50[113]$ & Multifilament[113] \\
\hline
\end{tabular}




\subsection{Non-bioabsorbable meshes}

Non-bioabsorbable meshes can be classified into reticular, laminar or combined structures (see Table 1). Thus, reticular meshes include polypropylene meshes that are excellent to close major hernia defects and can be used by surgeons for very complicated hernias due to the material requiring less general dissection [114]. A PP mesh hernioplasty requires a minimum operating time and its simplicity reduces surgical deficiencies leading to an insignificant recurrence rate, which exceeded 12 months in $95 \%$ of the cases and occasionally reached 5 years [115]. One of the most common prosthetics used in clinical practice is the Optilene ${ }^{\circledR}$ lightweight PP mesh. This mesh was compared with a large-pore knitted polytetrafluoroethylene (PTFE) mesh and both meshes showed comparable biocompatibility regarding chronic inflammatory reaction [116]. Its good tissue integration and good tissue adhesion characteristics ,make PP meshes suitable for hernia repair surgery. However, the highly non-reactive thermoplasticreticula PVDF is used to produce suitable meshes named Dynamesh $^{\circledR}$ for laparoscopic incisional and parastomal hernia interventions [117]. Long-term animal model experiments have shown a reduced foreign-body reaction to PVDF meshes [118]. A hybrid polypropylenebased reticula mesh is Dynamesh ${ }^{\circledR}$-IPOM that contains PVDF and compared with the non-biodegradable reticular Parietex ${ }^{\circledR}$ polyester mesh, produces a reduced incidence of recurrence, seroma and haematoma, although an increased incidence of adhesion-related bowel obstruction [119]. Parietex ${ }^{\circledR}$ meshes are commonly used as synthetic prosthetic with a long track record of clinical efficacy for tension-free hernia repair $[38,120]$ and offer enhanced compliance, excellent laparoscopic handling, and good local tolerance [121]. On the other hand, titanium-coated polypropylene reticular meshes have shown lower postoperative pain (short term), less analgesic use and faster recovery than the Parietex ${ }^{\circledR}$ mesh in the laparoscopic intraperitoneal onlay mesh (IPOM) technique [103]. This study analysed the most common titanium-coated PP meshes including TiMesh produced by plasma coating of atomic titanium and BioCer with a coating of $\mathrm{TiO}_{2}$. Reticular meshes made of PP with a coating of nano-crystalline silver (Optilene Silver Mesh ${ }^{\circledR}$ from Braun) provide the only antimicrobial mesh currently used in clinics [122]. Regarding the laminar meshes, in a prospective study with 86 patients having incisional or ventral hernias who used laminar Gore-Tex ${ }^{\circledR}$ mesh in laparoscopic repairs, an average hospital stay of 4.8 days was achieved [123]. Gore-Tex ${ }^{\circledR}$ meshes thus proved to be effective as they reduce pain, complications, hospital stays, and recurrence [123]. The use of Gore-Tex ${ }^{\circledR}$ for congenital diaphragmatic hernia repair was compared to Surgisis ${ }^{\circledR}$, a biological mesh composed of porcine small intestinal submucosa (SIS) and showed no significant difference in recurrent herniation rates between Surgisis ${ }^{\circledR}(44 \%)$ and Gore$\operatorname{Tex}^{\circledR}(38 \%)$ [124]. Furthermore, both groups showed similar recurrence times and most of these recurrences occurred after the first year [125]. The use of a laminar expanded polytetrafluoroethylene (ePTFE) Dual Mesh ${ }^{\circledR}$ (Gore) showed no significant avascular visceral adhesions 2-weeks after implantation in $91 \%$ of the patients with intraabdominal hernia repairs [126].

Ventralex ${ }^{\mathrm{TM}}$ hernia patch hybrid meshes made of polypropylene and ePTFE offer a valuable alternative for several hernia repair types: epigastric, umbilical, and small incisional hernias [127]. However, Ventralex ${ }^{\mathrm{TM}}$ Hernia Patch showed minimal postoperative morbidity (2 patients of 101) and a low recurrence rate (2\%) in a long-term follow-up (range 6-55) in a small ventral abdominal wall by intraperitoneal mesh repair [128].

\subsection{Partially bioabsorbable meshes}

Partially bioabsorbable meshes can be classified according to composite and autoadhesive composite material structure (see Table 1). Partially bioabsorbable composite meshes include PP-based meshes with PEG, Polyester meshes with PEG, PP-based meshes with poliglecaprone (Ultrapro ${ }^{\text {TM }}$ Mesh), PP-based meshes with polydioxanone (PDO) and oxidated regenerated cellulose (Proceed ${ }^{\mathrm{TM}}$ Ventral Patch), PP-based meshes with hydrophilic layer of HA and carboxymethylcellulose (CMC) such as Sepramesh ${ }^{\circledR}$ and PP-based meshes with PGA fiber with a coating of hyaluronic acid (HA), CMC, and polyethylene glycol (PEG) (Ventralight $\mathrm{ST}^{\circledR}$ ). Ultrapro $^{\mathrm{TM}}$ is a lightweight mesh that has shown disadvantages regarding chronic postoperative pain, recurrence and is more expensive than standard heavyweight meshes in TEP laparoscopic inguinal hernia repair [129]. A conventional heavyweight standard polypropylene $10 \mathrm{x} 15$ mesh is thus more suitable for laparoscopic inguinal hernia repair and has good biocompatibility [130]. Proceed Ventral meshes are used for ventral and incisional hernia repair [131]. This mesh is safe and effective and its performance is comparable with that of the Ventralex ${ }^{\mathrm{TM}}$ Hernia Patch (PP/ePTFE) [131]. Sepramesh ${ }^{\circledR}$ is a composite mesh made of PP monofilaments and is coated on one side with Seprafilm, a hydrogel safety coating composed of sodium 
hyaluronate (HA) and $\mathrm{CMC}$, which biodegrades at a speed that allows visceral protection during the critical healing process [132] and has been shown to be effective in reducing the likelihood of adhesions to surgical incisions $[133,134]$. The Ventralight $\mathrm{ST}^{\circledR}$ mesh is a complex composite that minimizes adhesion by placing the PGA-coated side towards viscera [37].

On the other hand, PP/PEG/PVP (Adhesix ${ }^{\circledR}$ ), PP/PLA (Parietene ${ }^{\mathrm{TM}}$ Progrip $^{\mathrm{TM}}$ ) and PE/PLA (Parietex ${ }^{\mathrm{TM}}$ Progrip $^{\mathrm{TM}}$ ) are partially biodegradable autoadhesive meshes. Two self-adhering meshes (Parietene ${ }^{\mathrm{TM}}$ ProGrip ${ }^{\mathrm{TM}}$ and Adhesix ${ }^{\circledR}$ ) were studied in a rat model and showed minimal foreign body reaction in both groups but better mechanical grip fixation for the Parietene ${ }^{\mathrm{TM}}$ ProGrip ${ }^{\mathrm{TM}}$ for hernia repair [135]. The role of mesh fixation is important in the endoscopic technique because penetrating techniques offer a good chance of developing a post-herniotomy pain syndrome. Self-adhering thus meshes play a fundamental role today. The recovery after inguinal hernia interventions with Parietex ${ }^{\mathrm{TM}}$ Progrip $^{\mathrm{TM}}$ showed that this type of mesh is able to significantly reduce the surgery time [136]. A new innovative line of research is the manufacture of self-adhesive meshes based on a biodegradable gelatin layer (LifeMesh ${ }^{\mathrm{TM}}$ ) and PP with largepores and lightweight for hernia repair[137]. In a comparative study between the composite LifeMesh ${ }^{\mathrm{TM}}$ and PP meshes, LifeMesh ${ }^{\mathrm{TM}}$ showed good tolerance and its implantation did not lead to any adverse local reaction. Its adhesive layer degraded during the 4 weeks after implantation and a histopathological examination revealed that the presence of the adhesive contributed to a uniform thickness of the granulation tissue surrounding the mesh, suggesting that the mesh will better integrate with the abdominal wall. The use of this type of mesh resulted in less adherence to the internal organs, which is very important in preventing adverse effects [137].

\subsection{Bioabsorbable meshes}

Biodegradable meshes provides the advantage of being bioabsorbable and thus can repair hernias avoiding a second surgery procedure [138]. Biodegradable meshes can be produced from biological tissues as biological meshes, by degradable biosynthetic polymers and by biodegradable synthetic polymers [139]. However, synthetic or biosynthetic bioabsorbable meshes are more economic than biological meshes [138]. Nonetheless, it is important to underline that all these bioabsorbable meshes are much more expensive than the permanent non-bioabsorbable PP mesh such as Optilene ${ }^{\circledR}$.

\subsubsection{Biological bioabsorbable meshes}

Biological grafts were introduced for hernia repair applications as alternative biomaterial to synthetic meshes with the goal of reducing post-operative complications [140]. Biologically derived meshes are matrices produced by tissue decellularization [141] to reduce the risk of infections and foreign body reaction, although there is still some controversy in this regard [141,142]. These collagen-based structures can positively influence wound healing due to their intrinsic biological properties by fast angiogenesis and tissue regeneration $[143,144]$. Porcine derived tissues isolated from the dermis (Permacol ${ }^{\mathrm{TM}}$ from Tissue Science Laboratories [145] and Strattice ${ }^{\mathrm{TM}}$ ) or from the SIS (Surgisis ${ }^{\circledR}$ from Cook Surgical) [146] have been the most extensively implanted matrices. Although Permacol ${ }^{\mathrm{TM}}$ is safe and feasible, Surgisis ${ }^{\circledR}$ in a comparative study showed improved strength of incorporation and enhanced collagen deposition and neovascularization after 60 days [145]. Permacol ${ }^{\mathrm{TM}}$ meshes are seldom used for abdominal wall hernia repair due to their price and because there are better alternatives. Thus, SIS mesh has been applied successfully for inguinal and paraesophageal hernia repair and for enterocutaneous fistula and bile duct repairs in recent years [147-150]. SIS mesh has also been found to be a good option for the repair of potentially contaminated ventral hernias [151,152] and is also used in other biomedical fields such as bladder regeneration [153]. Other common meshes produced from acellular derived tissues are those obtained from bovine pericardium (Veritas ${ }^{\circledR}$ ) and from human cadaver skin (Alloderm ${ }^{\circledR}$ LifeCell/Flex HD $^{\circledR} /$ Allomax $^{\mathrm{TM}}$ ). Human acellular dermis is safe and more effective for ventral hernias on contaminated welds [154,155].

Biological meshes are especially useful for the reconstruction of trunk defects when infection of the wound or mesh can lead to a hernia after reconstruction of the abdominal wall [156]. However, biological meshes have very high costs, which means that they cannot be used for routine reconstruction of the abdominal wall [157]. As such, some surgeons only use this type of mesh for the repair of complex defects of the abdominal wall [157-159]. In addition, acellular dermal meshes may produce infection, seroma, wound dehiscence in the short-term and mesh infection and recurrence complications in the long-term, as well as hernia recurrences 
$[160,161]$. Therefore, although this type of repair can produce satisfactory results in some cases, it is far from being a definitive method of hernia repair. To tailor the degradation speed of the mesh and increase its stability to enzymatic decomposition, chemical crosslinking reactions can be carried out, using hexamethylene diisocyanate (HMDI), 1-ethyl-3- (3-dimethylaminopropyl) carbodiimide hydrochloride (EDAC) or genipin [162-164]. However, crosslinking density may limit tissue growth and hinder or reduce the pore size, providing a suitable housing for bacteria and may even promote fibrotic encapsulation $[165,166]$. These types of meshes are not used for inguinal hernia. In abdominal wall repair they are used less and less due their high price and the existence of better alternative options.

\subsubsection{Biosynthetic bioabsorbable meshes}

Biosynthetic biodegradable meshes mainly include those based on silk fibre, gelatin, polyhydroxyalkanoates (PHAs) and plant fibre-based materials. Thus, insect-based protein-based products such as silk fibre extracted from silkworms, Bombyx mori, with remarkable mechanical properties and reabsorption time of 2 years have gained attention to compete with biological matrices [167]. Recent research has focused on the use of natural biopolymers such as silk fibre [168-172]. Other biosynthetic polymers such as bacterial poly(4hydroxybutyrate) $(\mathrm{P} 4 \mathrm{HB})$ have been used to developed bioabsorbable meshes such as Phasix ${ }^{\mathrm{TM}}$. This type of mesh is a fully resorbable monofilament scaffold for rapid tissue incorporation that have shown an in vitro and in vivo degradation with $80 \%$ and $18 \%$ greater strength than native abdominal wall at 8 and 72 weeks post-implantation, respectively, despite the significant biopolymer degradation [112]. P4HB reabsorbable meshes are showing promising results in the management of chronic mesh infection [173-175]. The electrospun silk fibroin (SF) in combination with other PHA with excellent biological properties, poly (3hydroxybutyrate-co-3-hydroxyvalerate) (PHBV) [176,177], to produce hybrid scaffolds have showed high efficiency and biocompatibility to repair abdominal wall defects [178]. The use of plant-derived fibers as mesh materials for abdominal wall repair is also being studied [179]. These meshes showed biosecurity both in vitro and in vivo, but only in those where intensive purification steps were applied after various chemical treatments. The silk fibre, gelatin and plant-fibee-based meshes are not yet being used in clinics. However, bacterial Phasix meshes are currently used in hospitals such as La Fe in Valencia, Spain. This prosthesis, like the bioabsorbable synthetic BIO-A described below, has been used in cases of complex eventrations with contaminated or dirty surgeries (grade III and IV of the Centers for Disease Control (CDC) classification) or in cases of chronic infection of the mesh (biofilm). There is no consensus on the use of this type of material in contaminated fields since there are working groups that defend the use of permanent synthetic materials [180].

\subsubsection{Synthetic bioabsorbable meshes}

Synthetic biodegradable meshes include those based on biodegradables synthetic polymers such as poly- $\varepsilon$ caprolactone (PCL), polyglicolic acid (PGA), polylactic acid (PLA) and the copolymer poly(lactic-coglycolic) (PLGA). Although initially widely used, PGA meshes are not used any more because they degrade too fast [181]. Since PLA degrades slower than PGA, a mesh named POLYGLACTIN 910 (Vicryl ${ }^{\mathrm{TM}}$ ) was developed by Ethicon. This mesh is composed of $92 \%$ glycolide copolymerized with $8 \%$ lactide [151]. However, this type of mesh also has some complications such as the fact that it does not prevent post-operative recurrence of herniation, probably because of an inappropriate degradation rate $[113,182]$. Synthetic biodegradable scaffolds of $67 \%$ PGA copolymerized with $33 \%$ trimethylene carbonate (TMC) such as PGAPTMC (BIO-A ${ }^{\circledR}$ ) from Gore, also known as Gore ${ }^{\circledR}$ BIO-A, have shown significantly better tissue integration and resistance than that obtained with biological matrices such as Strattice ${ }^{\mathrm{TM}}$ and Veritas ${ }^{\circledR}$, and the native abdominal wall $[40,183]$. BIO- $\mathrm{A}^{\circledR}$ meshes have also shown improved properties in comparison with common biological meshes. Complex open bioabsorbable reconstruction of the abdominal wall (COBRA) studied the results of $\mathrm{BIO}-\mathrm{A}^{\circledR}$ in contaminated fields II and III of the CDC classification and concluded that it showed efficacy in terms of long-term recurrence and quality of life for complex ventral hernia repair and offers an alternative to biological and permanent synthetic meshes in these complex situations [184]. Prospective multicentre studies have also described its usefulness in repairing complex herniations [185]. PLA-based meshes from Ethicon composed of 95\% Lactide and 5\% glycolide provide further improved mechanical properties for more than 9 months [113]. However, PLA-based meshes also present complications such as foreign body granuloma and giant cell formation. 


\section{Mesh adhesion problem}

Due to their good performance in abdominal wall hernia repair and lower cost than those of other available options, PP mesh is the most broadly used [186]. However, this type of mesh frequently induces dense adhesions due to fibrovascular infiltration when there is direct contact between the mesh and the viscera [187] and if the mesh is placed directly over the intestine and other visceral organs $[134,188]$. Mesh adhesion may cause obstruction and perforation of the bowel and thus is one of the main problems that arise after the treatment of hernias and can cause discomfort and generate adverse reactions [189]. Difficult reoperation, intestinal obstruction, or enteric fistula may be led by mesh adhesions [187]. Intestinal and omentum tissue have exhibited severe adhesions to common meshes such as PP, which may cause many serious complications [190]. To try to solve these problems, ePTFE meshes, like Gore-Tex ${ }^{\circledR}$ were used since they cause less adhesion to the intestine due to their microporous surface morphology. However, the tensile strength in their interface is lower than in the PP mesh or composite mesh made of PP and ePTFE [191]. In addition, when the ePTFE mesh becomes infected, recovery is very difficult, and the mesh usually requires removal [192,193]. Research on the development of new materials and coatings as strategies to prevent adhesion is therefore essential in this field. The adhesion problem has promoted the development of a composite mesh that combines two or more materials made of a non-absorbable material such as polypropylene, polyester or PVDF on one face and a non-adhering biodegradable material on the face in contact with handles or viscera, such as ePTFE, PLA, etc [37].

\section{Chronic mesh infection problem}

Prosthetic materials for hernia repair often present infection by bacteria on the material surface that results in failure of the implanted meshes [194-197]. Two examples of chronic bacterial infections (biofilm) are shown in Figure 2.
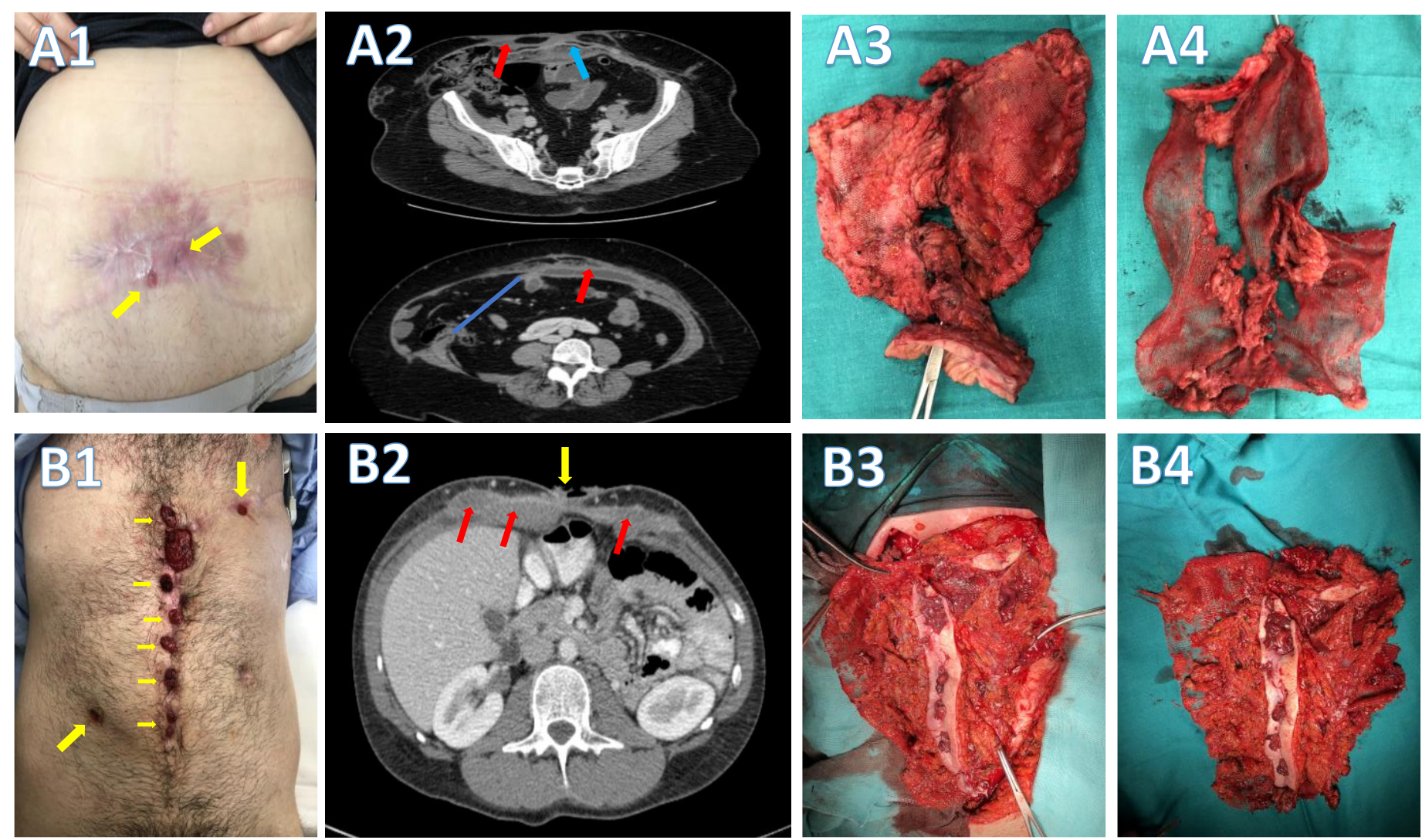

Figure 2. Examples of meshchronic infections. Biofilm case A: 50-year-old woman with recurrent incisional hernia (10 previous interventions with placement of several prosthesis). She presented two fistulous orifices with chronic suppuration (yellow arrows) (A1). The microbiological analysis showed infection by Staphylococcus aureus. The tomography (A2) shows a large lateral incisional hernia (blue line), postsurgical changes in the anterior abdominal wall associating collection of $15 \mathrm{x} 13 \mathrm{x} 1.2 \mathrm{~cm}$ (transverse / craniocaudal / anteroposterior) (red arrows) and one of the prostheses previously placed (blue arrow). Removal of 2 
previous prostheses (A3 placed onlay and A4 preperitoneal) and reconstruction of wall with placement of a 4 PHB prosthesis (Phasix ${ }^{S T}$ ) was required. Biofilm case B: 26-year-old man who needed several laparotomies due to traffic accident with placement of PVDF prosthesis. Four months later he presented multiple fistulous orifices with chronic suppuration (yellow arrows) (B1). The microbiological analysis showed infection by Staphylococcus aureus and Pseudomonas aeruginosa. The tomography shows an anfractuous collection on the prosthesis (red arrows) and fistulous orifices (yellow arrows) (B2). Complete removal of the PDVF prosthesis was required (B3 and B4).

Figure 2 shows two examples of the problem of chronic mesh infections where bacterial biofilm was formed and complicated the search for a satisfactory solution. The microbiological cultured in these two cases showed infection by Staphylococcus aureus and by Pseudomonas aeruginosaalso in the second case.

S. aureus [198] and Staphylococcus epidermidis [199] are the most common microorganisms related to mesh infection (approximately 90\%), S. aureus (MRSA) [200], involved in up to 63\% of surgical site mesh-related infections [201-203], being methicillin-resistant. Other microorganisms related to mesh infection include Streptococcus pyogenes [204], Enterococcus faecalis [205,206], Pseudomonas sp.[204], Escherichia coli, Klebsiella pneumonia [207,208], Propionibacterium acnes and Candida albicans [209-211].

\section{Antimicrobial meshes and their fabrication methods}

Most common prosthetic meshes used for hernia repair (Table 1) are made of materials that do not possess antimicrobial activity. However, surgical infections have an increasing clinical, economic and socioeconomic impact due to the cost of managing infectious complications in digestive surgery, triple the total direct cost of surgery and the patients' reduced quality of life of patients and affect waiting lists [212,213]. In this regard, the coating of biomaterials with antimicrobial compounds is the most common technique to provide antimicrobial properties to the surface and thus prevent microbial colonization and attachment [214,215]. Antimicrobial meshes can be made by dipping/soaking, plasma surface functionalization, plasma-induced graft polymerization [216] (see Figure 3).

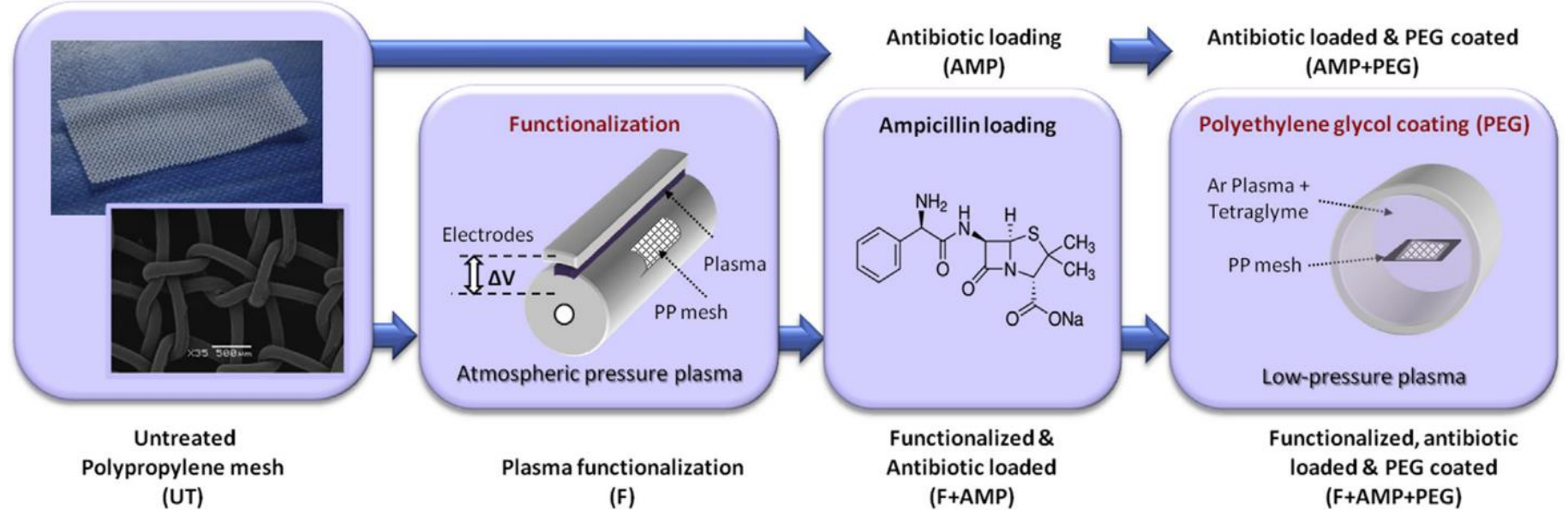

Figure3. Manufacturing scheme of PP meshes with enhanced biological properties through plasma functionalization, antibiotic load and plasma polymerization of a polyethylene glycol coating. Reprinted with permission from Elsevier [216].

The antibiotic dipping/soaking method [217-220], antiseptics [221] and enzymes [222,223] dissolved in a liquid solution (usually aqueous) that are physically adsorbed onto the mesh. This technique, while useful, has not demonstrated clinical superiority over systemic antibiotic therapy. In addition, it presents the limitation of providing a short-term period of infection prevention. Plasma treatment of the matrices triggers the formation of intermediate reactive species and functional groups on the mesh surfaces that enhance the interaction between the drug and the surface [216]. Plasma can also be used to produce anchor points on the mesh surface for monomer polymerization as plasma-induced graft polymerization [224-227]. The plasma treatment and plasma-induced graft polymerization provide longer-lasting antimicrobial options [216,225,228,229]. 3D printing is another available method of producing antimicrobial meshes selected by some researchers, also referred to as rapid prototyping or additive manufacturing, by different 3D printing mechanisms: stereo lithography, selective laser sintering, injection printing, or fused deposition modelling (FDM) [230]. FDM consists of extruding a polymer filament after heating to its melting temperature and is the most promising technique due to its lower-cost and the possibility of producing personalized hernial meshes [230]. 
All of the antimicrobial meshes shown in this section are currently under research and only the silver-coated polypropylene mesh (Optilene Silver Mesh ${ }^{\circledR}$ from Braun) shown in Table 1 has recently started to be used on a limited number of patients with ventral hernias in hospitals such as the Spanish Hospital La Fe. However, these meshes are only being applied in special cases such as patients with incisional hernias who are at risk of infection, i.e. contaminated grade III or clean contaminated II of the CDC classification. The manufacturer of this type of mesh would like to broaden the application to the rest of the grades but further scientific research is required to achieve this goal. Although there are really no tests with a high degree of recommendation that determine the type of mesh to be used in each case and surgeons must decide according to their own experience. According to the manufacturer, silver ions $\left(\mathrm{Ag}^{+}\right)$provide a broad spectrum antimicrobial action, the release of the silver ion is gradual and sustained over time, which allows better prevention of infection, and their use is safe in the long term, does not present toxicity or generate resistance [231]. However, many scientific studies have demonstrated that silver ions can be highly toxic for mammalian cells [232,233] and induce microbial resistance [234,235]. Further research is therefore necessary in this field to find a solution to avoid microbial infections, including those strains that are multidrug-resistant. The optimal hernia repair mesh would be ideally made of a material able to deal with microbial resistance to provide a long-lasting solution. In this regard, a broad range of antimicrobial meshes have been proposed so far (see Table 3 ). 


\section{Table 3. Promising antimicrobial meshes for hernia repair.}

\begin{tabular}{|c|c|c|c|c|c|c|c|}
\hline Mesh material & Antimicrobial agent & $\begin{array}{c}\text { Microorganism } \\
\text { tested }\end{array}$ & Antimicrobial activity & Cytotoxic effect & $\begin{array}{c}\text { In vivo tested } \\
\text { (animal model) }\end{array}$ & Year & Ref. \\
\hline \multicolumn{8}{|l|}{ Meshes with antibiotics } \\
\hline Polyester & Coating with CD-PEGDGE and vancomycin & S. aureus & Yes, against $S$. aureus & Not tested & Yes (mouse) & 2010 & [236] \\
\hline PGA-TMC & Cefazolin & S. aureus & Yes, against $S$. aureus & Not tested & Yes (rats) & 2015 & {$[220]$} \\
\hline $\begin{array}{l}\text { Porcine acellular dermal } \\
\text { matrix }\end{array}$ & Rifampin/minocycline & E. coli and MRSA & Yes, against $E$. coli and MRSA & No & Yes (rabbit) & 2016 & [237] \\
\hline Polyester (Parietex®) & Cyclodextrin-based polymer loading Vancomycin & MRSA & Yes, against MRSA & Not tested & Yes (pig) & 2017 & {$[238]$} \\
\hline PLLA & Ciprofloxacin & S. aureus and E. coli & Yes, against S. aureus and E. coli & No & No & 2017 & [239] \\
\hline PP & Coating with PLGA-rifampicin microspheres & S. aureus & Yes, against $S$. aureus & $\begin{array}{l}\text { No (human fibroblasts } \\
\text { from foreskin) }\end{array}$ & Yes (mouse) & 2017 & [240] \\
\hline PP grafted with HDI-CD & Levofloxacin & S. aureus and E. coli & Yes, against S. aureus and E.coli & Not tested & No & 2018 & [241] \\
\hline PBSA & Levofloxacin & S. aureus and E. coli & Yes, against $S$. aureus and E. coli & $\begin{array}{c}\text { No (Mouse fibroblast } \\
\text { L929) }\end{array}$ & Yes (mouse) & 2019 & [242] \\
\hline Different meshes & HApN with gentamicin/ rifampicin & $\begin{array}{l}\text { S. aureus, MRSA, } S \text {. } \\
\text { epidermidis, E. coli }\end{array}$ & $\begin{array}{l}\text { Yes, aginst } S \text {. aureus, MRSA, S. epidermidis and } \\
\text { less against } E \text {. coli }\end{array}$ & No & No & 2019 & {$[243]$} \\
\hline PVA and PP & Ciprofloxacin hydrochloride & Not tested & Not tested & No & Yes (rabbit) & 2019 & {$[90]$} \\
\hline \multicolumn{8}{|c|}{ Meshes with antimicrobial metals } \\
\hline PP & $\mathrm{Ag} /$ Silica & S. aureus & Yes, against $S$. aureus & No & No & 2016 & [244] \\
\hline 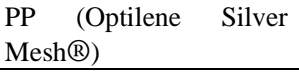 & Nano-crystalline silver coating & MRSA & Yes & Not tested & Yes (rats) & 2018 & [122] \\
\hline PP & Zinc & In vivo & Yes (In vivo) & No tested & Yes & 2020 & [245] \\
\hline \multicolumn{8}{|c|}{ Meshes with antimicrobial polymers } \\
\hline Silk fibroin & Blended with Chitosan & Not tested & Not tested & Not tested & Yes (guinea pigs) & 2006 & [246] \\
\hline Chitin & Chitin & Not tested & Not tested & Not tested & Yes (rats) & 2017 & [247] \\
\hline Chitin & Chitin & Not tested & Not tested & Not tested & Yes (rats) & 2018 & [248] \\
\hline \multicolumn{8}{|l|}{ Meshes with antiseptics } \\
\hline PP & Chlorhexidine and Allicin & S. aureus & Yes, against $S$. aureus & $\begin{array}{l}\text { Yes (rabbit skin } \\
\text { fibroblasts) }\end{array}$ & No & 2015 & [249] \\
\hline PP & Chlorhexidine and Allicin & S. aureus & Yes, against S. aureus & Not tested & Yes (rabbit) & 2015 & [221] \\
\hline PP (Optilene $\left.{ }^{\circledR}\right)$ & QA-based polymer loaded with chlorhexidine & $\begin{array}{l}\text { S. aureus, E.coli and } S \text {. } \\
\text { epidermidis }\end{array}$ & Yes, against $S$. aureus, E.coli and S. epidermidis & $\begin{array}{l}\text { Yes (rabbit skin } \\
\text { fibroblasts) }\end{array}$ & No & 2016 & [250] \\
\hline PP grafted with HDI-CD & Triclosan & S. aureus and E. coli & Yes, against $S$. aureus and E.coli & Not tested & No & 2018 & [251] \\
\hline PP (Optilene $\left.{ }^{\circledR}\right)$ & Chlorhexidine-loaded carboxymethylcellulose gel & S. aureus & Yes, against $S$. aureus & $\begin{array}{l}\text { Low (rabbit skin } \\
\text { fibroblasts) }\end{array}$ & Yes (rabbit) & 2019 & [252] \\
\hline \multicolumn{8}{|c|}{ Meshes with antimicrobial peptides } \\
\hline PP with PCL & AMPs in gellan gum & S. aureus and E. coli & Yes, against $S$. aureus and E.coli & No (HDFs) & No & 2019 & [253] \\
\hline PP & AMP (PEP-1) in PCL & E. coli and S. aureus & Yes, against E. coli & No (HDFs) & No & 2019 & [254] \\
\hline \multicolumn{8}{|c|}{ Meshes produced by combined strategies } \\
\hline PP & Triclosan-chitosan coating & S. aureus & Yes, against $S$. aureus & Not tested & Yes (rats) & 2009 & [255] \\
\hline ePTFE & silver carbonate and chlorhexidine diacetate & S. aureus & Yes, against S. aureus & Not tested & Yes (rabbit) & 2015 & {$[221]$} \\
\hline PLLA & MSN of levofloxacin and silver & MRSA & Yes, against MRSA & No & Yes (rat) & 2017 & {$[256]$} \\
\hline PCL & Levofloxacin and irgasan & S. aureus and E. coli & Yes, against $S$. aureus and $E$. coli & Not tested & No & 2017 & [257] \\
\hline PCL & Alginate and gentamicin & E. coli & Yes, against E. coli & Not tested & Yes (rats) & 2019 & [258] \\
\hline Polyester & $\begin{array}{l}\text { Coating of chitosan-phenytoin-pluronic } \\
\text { nanomicelles and ciprofloxacin-alginate }\end{array}$ & $\begin{array}{l}\begin{array}{l}\text { aureus and } \\
\text { aeruginosa }\end{array} \\
\text { a. }\end{array}$ & Yes, against $S$. aureus and $P$. aeruginosa & Not tested & Yes $(\operatorname{dog})$ & 2019 & [259] \\
\hline $\begin{array}{ll}\begin{array}{l}\text { Nylon-6 (core) } \\
\text { poly(hexanide) }\end{array} & \text { with } \\
\end{array}$ & $\begin{array}{l}\begin{array}{l}\text { Chitosan/Polyethylene oxide (shell) with 5- } \\
\text { chloro-8-quinolinol }\end{array} \\
\end{array}$ & $\begin{array}{l}S . \text { aureus and } P . \\
\text { aeruginosa }\end{array}$ & Yes, against $S$. aureus and $P$. aeruginosa & Not tested & No & 2020 & {$[260]$} \\
\hline PP (Optilene $囚)$ & Chlorhexidine fixed with cyanoacrylate adhesive & S. aureus & Yes, against $S$. aureus & Not tested & Yes (rabbit) & 2021 & [261] \\
\hline
\end{tabular}


Nevertheless, none of these meshes have been successful in clinical practice or have not yet been tested. They are classified according to their antimicrobial agents such as antibiotics, silver, antimicrobial polymers, antiseptics, antimicrobial peptides and by combined antimicrobial strategies.

\subsection{Meshes with antibiotics}

A polyester mesh was coated with $\beta$-cyclodextrin-Polyethylene glycol diglycidyl ether loaded with vancomycin and showed effective prevention of $S$. aureus mesh infection two and four weeks after implantation in vivo in a mouse animal model [236]. Prior to the clinical translation of these meshes, further studies including long-term evaluation and biocompatibility studies are needed. Other meshes that have already shown an evident decrease in bacterial colonization of the Gram-positive $S$. aureus are prostheses impregnated with the antibiotic cefazolin [220]. Although adhesions to the prosthesis were produced when it was placed in contact with intra-abdominal viscera, the antibiotic mesh reduced the formation of adhesions compared with the control group, besides inhibiting the inflammatory response to infection [220]. Another strategy proposed consisted of biological meshes to take advantage of their good compatibility, giving them antibacterial properties by charging them with antibiotics [237]. These researchers produced a porcine acellular dermal matrix mesh charged with minocycline and rifampin (XenMatrix $\mathrm{AB}$ ) that showed antimicrobial activity both in vitro and in vivo against $E$. coli and the life-threatening multidrug-resistant MRSA. XenMatrix AB exhibited complete bacterial inhibition, no abscess formation, and a reduced inflammatory response in an in vivo rabbit model compared with the uncoated meshes [237].

A significant reduction of antibiotic dose $\left(1.75 \mathrm{mg} / \mathrm{cm}^{2}\right)$ compared with systemic antibiotic administration was achieved in a pig model preventing a multifilament prosthetic mesh infection with a Parietex ${ }^{\circledR}$ polyester mesh with a crosslinked cyclodextrin-based polymer and incorporated vancomycin [238]. This small amount of vancomycin achieved complete elimination of the MRSA infection in the mesh implanted in six pigs without affecting tissue integration [238]. Another strategy consisted of thermofixating polycyclodextrin on a PLLA mesh [239]. This antimicrobial approach showed suitable release kinetics of ciprofloxacin to provide efficient antibacterial activity against $S$. aureus wand E. coli [239]. Polypropylene meshes coated with PLGArifampicin microspheres showed that this compound continuously releases over 60 days and provides potent antibacterial activity against $S$. aureusin vitro and in vivo and no adverse effects appeared against fibroblast cells for hernia repair [240]. The loading with levofloxacin and grafting of a PP mesh with hexamethylene diisocyanate (HDI) and cyclodexrins (CD) exhibited long-lasting antibacterial activity against E. coli and $S$. aureus [241]. Antibiotic (levofloxacin) surface modification of poly(butylene succinate-co-butylene aspartate) (PBSA2- $g-\mathrm{Lv}$ ) meshes achieved in vitro antibacterial capacity against $S$. aureus and $E$. coli without affecting the viability of L929 fibroblast cells [242]. These PBSA2- $g$-Lv meshes prevented bacterial infection and promoted tissue regeneration in an in vivo wound-healing mouse model (Figure 4) [242]. 


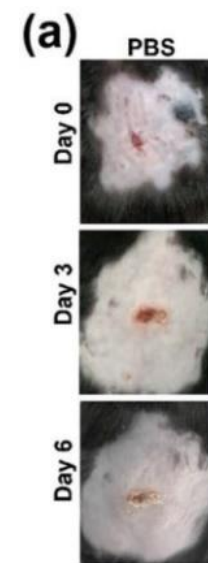

(c)

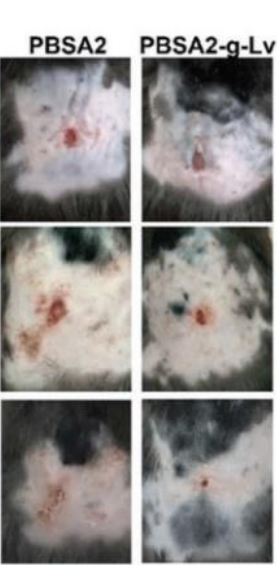

PBS
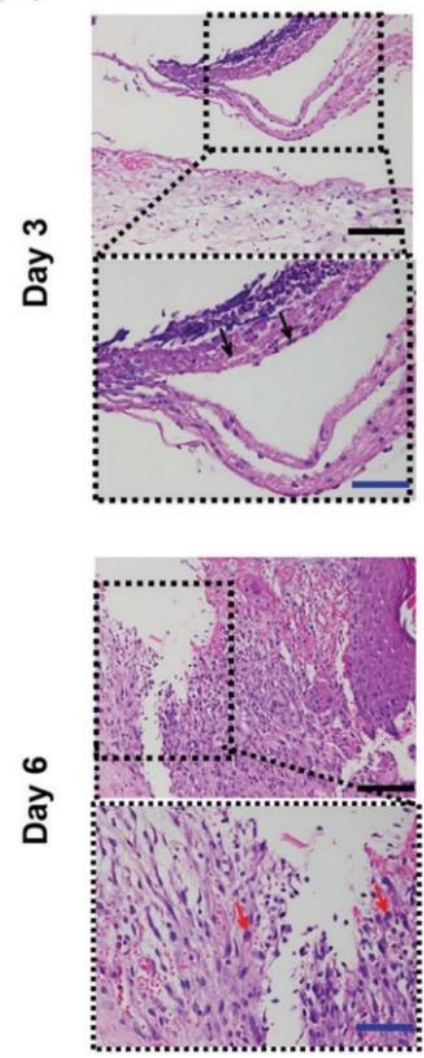

(b)

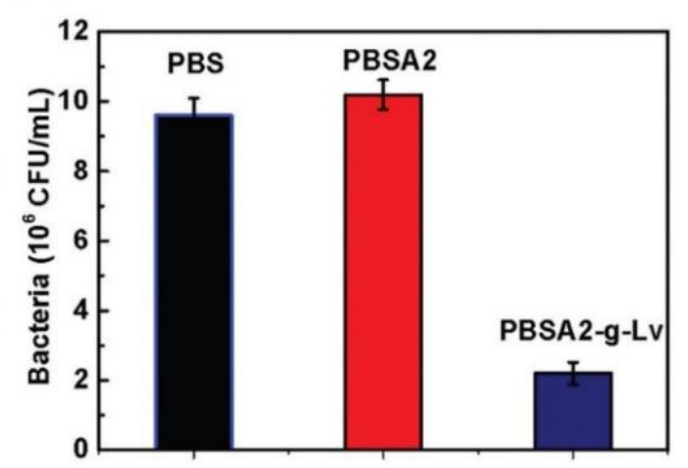

PBSA2
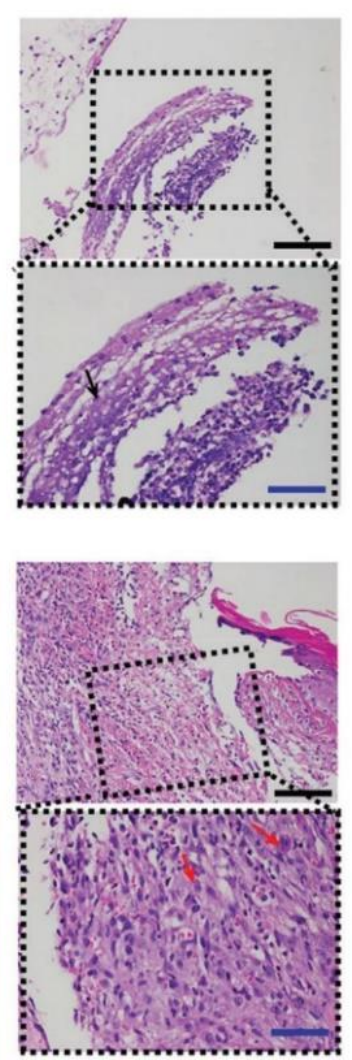

PBSA2-g-Lv
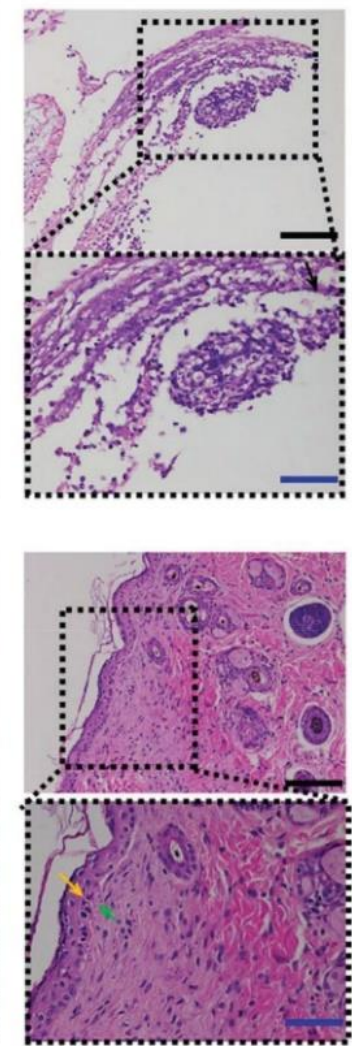

Figure 4. (a) Images of wounds treated with polyester electrospun nanofibre meshes of polybutylene succinate (PBS), poly(butylene succinate-co-butylene aspartate) (PBSA2) and poly(butylene succinate-co-butylene aspartate) with levofloxacin (PBSA2-g-Lv). (b) Bacterial concentrations measured in the wound tissue of a mouse animal model. (c) Hematoxylin and eosin staining after three and six days of treatment (the black and blue scale bars are $200 \mu \mathrm{m}$ and $100 \mu \mathrm{m}$, respectively) - Published by The Royal Society of Chemistry (RSC)[242].

A polymer-based hyaluronic acid-poly(N-isopropylacrylamide)(HApN) hydrogel that can be used as drugloaded coating of gentamicin and rifampicin applicable to different meshes to provide strong antimicrobial activity against $S$. aureus, MRSA, S. epidermidis and less against E. coliin vitro [243]. Polyvinyl alcohol (PVA) is another biomaterial hydrogel with excellent biocompatibility and water sorption properties [262]. Meshes with a broad range of porosities with pores of different shapes and sizes using different sized threads can be produced with PVA and PP loaded ciprofloxacin hydrochloride to minimize post hernioplasty infections by FDM 3D printing (see Figure 5) [90]. 

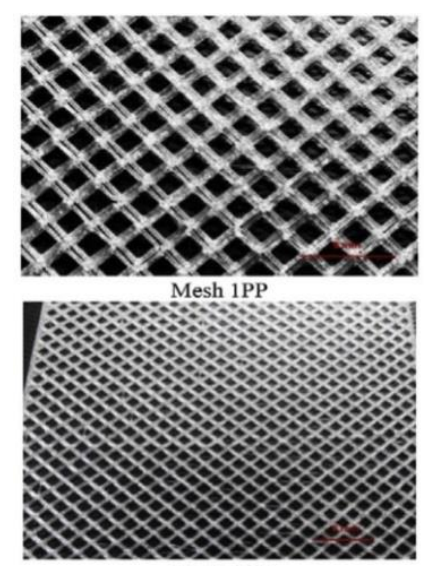

Mesh 3PP

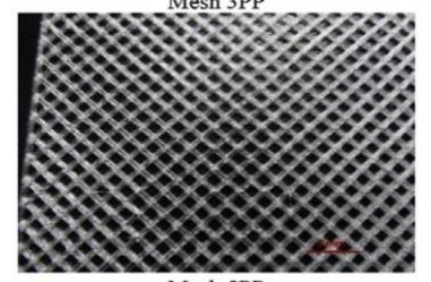

Mesh 5PP

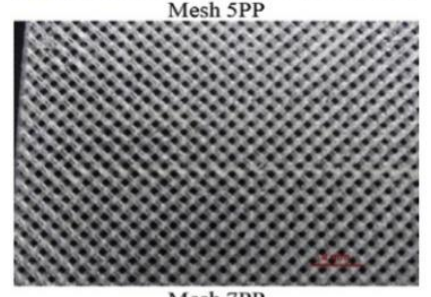

Mesh 7PP

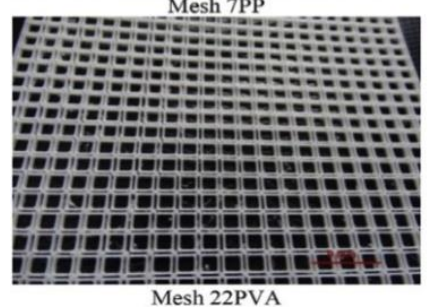

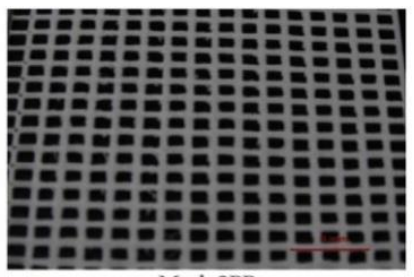

Mesh 2PP
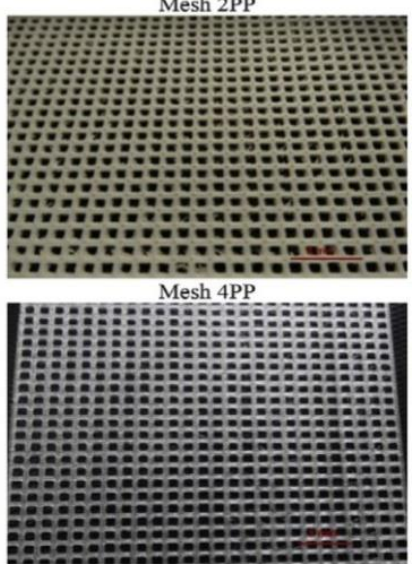

Mesh 6PP

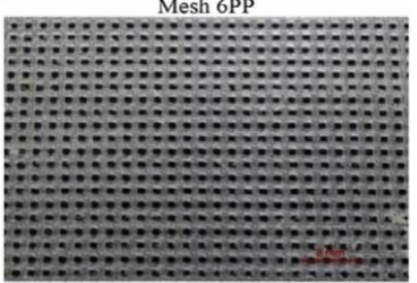

Mesh 8PP

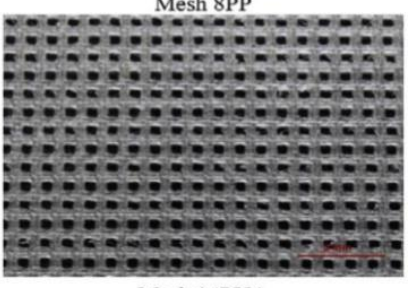

Mesh 24PVA

Figure 5. Pictures of different 3D printed antimicrobial meshes by FDM. Reprinted with permission from Elsevier [90].

All of the 3D printed antimicrobial meshes showed outstanding mechanical performance in vivo biocompatibility, adhesion capacity, mild-to-moderate appearance of adhesions to visceral tissue, and did not exhibit signs of implant rejection. However PVA-based meshes showed slightly faster drug release than PPbased meshes [90]. The development of new antimicrobial meshes against all types of microorganisms, including the multidrug-resistant strains, is becoming more important due to the global problem of the increasing antibiotics resistance repeatedly announced by the World Health Organization [52]. In this regard, many alternative antimicrobial meshes are currently under development by many international research groups.

\subsection{Meshes with antimicrobial metals}

Polypropylene meshes with a silica/silver layer have been proposed for hernia repair and showed good biocompatibility in peritoneal mesothelial cells and tissue repair [244]. An antimicrobial mesh made of PP (Optilene Silver Mesh ${ }^{\circledR}$ from Braun) with a coating of nano-crystalline silver showed significantly better bactericidal effect than the normal PP meshes [122]. Other metal-based meshes impregnating with Zinc (ZnMesh) have recently been proposed for abdominal wall repair and showed significant reduction of infection in a rat animal peritonitis model [245]. However, a higher percentage of adhesions were reported in this type of mesh than in conventional PP meshes.

\subsection{Meshes with antimicrobial polymers}

Natural materials such as chitosan with intrinsic antimicrobial activity combined with silk fibroin have been proposed to produce meshes for ventral hernia repair [246]. In this study, these meshes were tested in guinea 
pigs and compared with biodegradable human acellular dermal matrix and a PP mesh, which showed extensive intestinal adhesions and scarring in contrast to the other two meshes that underwent tissue remodelling. Another promising biodegradable hernia patch for repairing rat abdominal wall full thickness defects was made with another antimicrobial material, chitin [247]. The chitin patch induced more abundant new blood vessels with less tissue inflammation and fibrosis compared to PP mesh. In a subsequent study performed by the same authors, chitin patches showed good biomechanical properties and satisfactory healing effects on the abdominal wall, which render them promising for clinical hernia treatment [248]. However, the antimicrobial characterization of these promising chitin and silk fibroin/chitosan meshes have not yet been explored.

\subsection{Meshes with antiseptics}

Another strategy proposed by Perez-Köhler et al. consisted of soaking a reticular heavyweight PP mesh with antiseptics such as a mixture of chlorhexidine and allicin to inhibit Staphylococcus aureus adhesion [249]. Inhibition zones and SEM micrographs were compared with each compound separately and with the vancomycin antibiotic. While allicin alone lost its effectiveness after 24 hours, when applied together with chlorhexidine the antibacterial activity was greater than that of vancomycin. However, allicin and chlorhexidine exerted high cytotoxicity against rabbit fibroblasts in contrast to vancomycin [249]. For this reason, the same authors performed an in vivo study with these meshes in New Zealand White rabbits and compared them with the performance of a commercial antimicrobial mesh (Gore Dual Mesh Plus mesh ${ }^{\circledR}$ )[221]. The chlorhexidine pre-soaked mesh displayed antimicrobial activity without interrupting tissue integration. However, although the meshes of the allicin-chlorhexidine group showed new tissue formation, they contained abscesses and bacterial infections (see Figure 6).
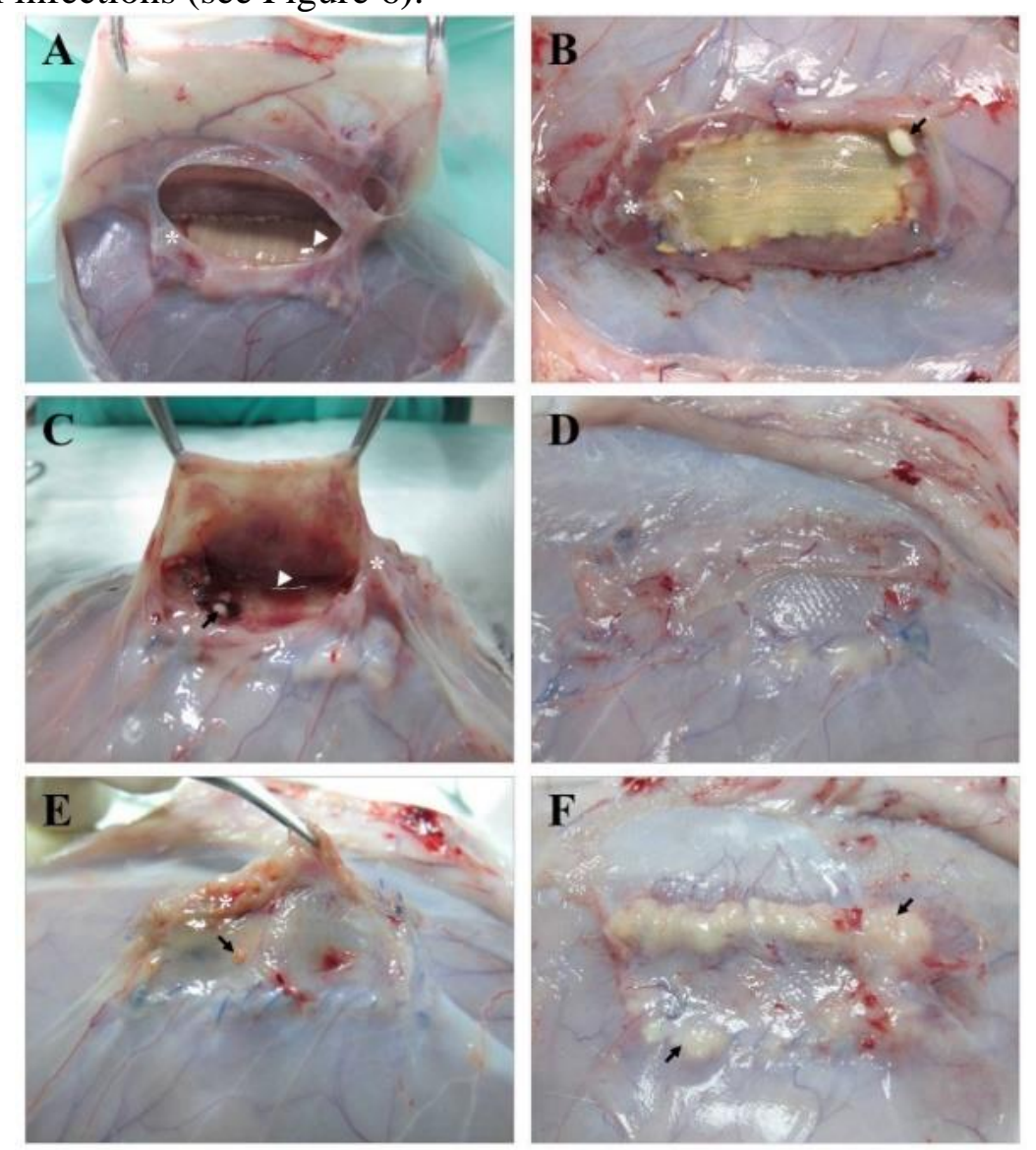

Figure 6. Prosthetic meshes for hernia repair after two weeks of surgery and S. aureus infection. (A, B) Laminar mesh of ePTFE with a coating of silver carbonate and chlorhexidine diacetate: clean main body, thick fibrous encapsulation $(*)$, seroma formation $(\rightarrow)$ and purulent material $(\rightarrow)$. (C, D) Polypropylene soaked with chlorhexidine implants showed more intense vascularization and a total mesh integration into the host tissue. (E, F) Polypropylene soaked with allicin-chlorhexidine meshes showed a high level of purulent material $(\rightarrow)$ on different parts of the mesh surface [221].

Soaking PP meshes with a low chlorhexidine concentration is thus a promising treatment to prevent and resist infection during hernia repair. In the same research line, the coating of polypropylene meshes (Optilene ${ }^{\circledR}$ ) with antibacterial quaternary ammonium-based polymer loaded with chlorhexidine (POL-CHX) meshes also 
showed antimicrobial activity [250]. In vitro antimicrobial assays against S. aureus, S. epidermis and E.coli showed significant inhibition halos around these composite meshes with the three bacteria strains: Gramnegative E. coli and Gram-positive $S$. aureus and $S$. epidermidis $(\mathrm{p}<0.01)$. However, this compound turned out to have some toxicity against human fibroblasts, significantly reducing its viability. In vivo performance in rabbits with partial abdominal wall defects were carried out with this type of mesh and showed maintenance of antimicrobial action and no bacterial adhesion 14 days after surgery. A PP mesh grafted with HDI and CD and loaded with triclosan showed excellent long-lasting antibacterial properties against $S$. aureus and E. coli [251]. Another strategy proposed more recently consisted of coating Optilene ${ }^{\circledR} \mathrm{PP}$ meshes with an antibacterial chlorhexidine-loaded carboxymethylcellulose gel [252].

\subsection{Meshes with antimicrobial peptides}

Alternative solutions to the exponential increase of antibiotic resistance are based on producing antibacterial composite meshes charged with wide-spectrum antimicrobial peptides (AMPs) [253] (Figure 7).

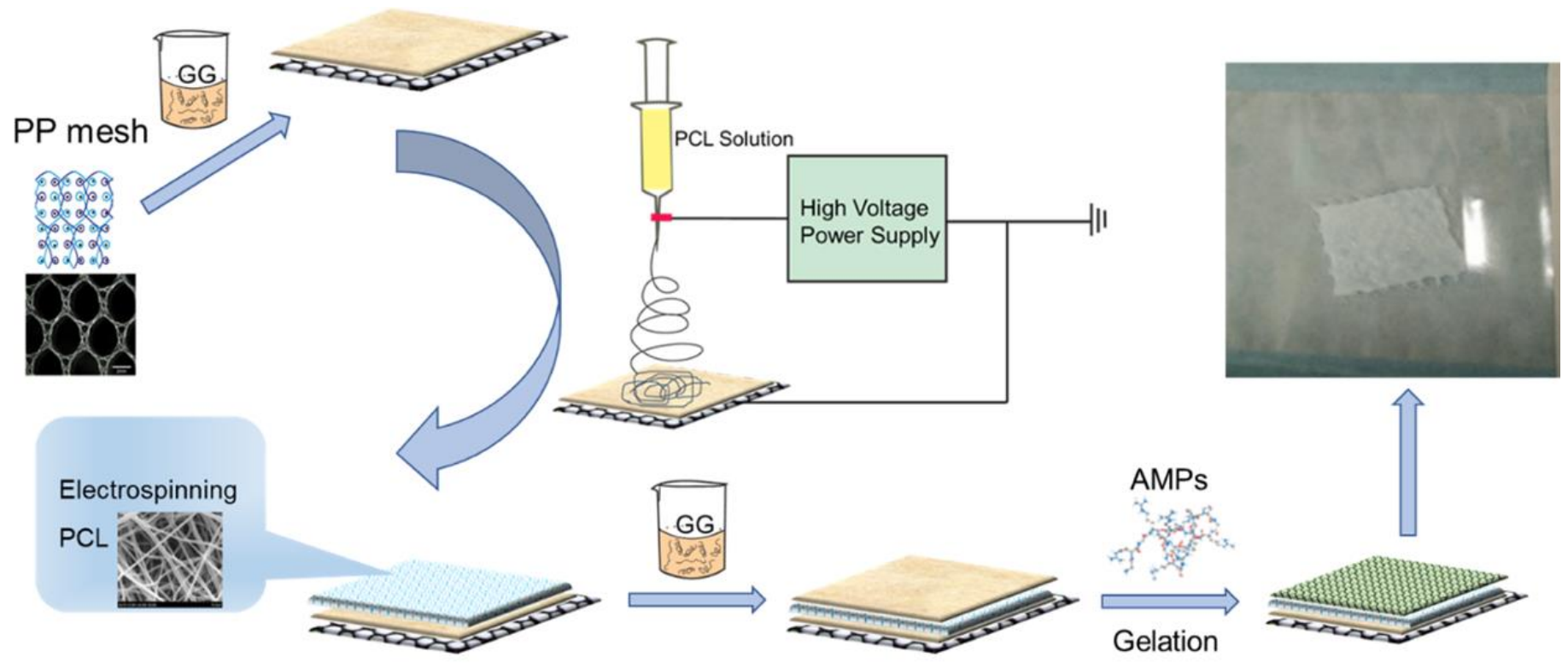

Figure 7. Manufacturing scheme of antimicrobial composite meshes made of a PP mesh and PCL electrospun nanosheets charged with wide-spectrum antimicrobial peptides (AMPs) incorporated in gellan gum. Reprinted with permission from ACS [253]. Copyright (2019) American Chemical Society. Further permissions related to the material excerpted should be directed to the ACS.

These novel antimicrobial meshes provided prolonged in vitro release of AMPs ( $<60 \%$ in 10 days) and thus potent antibacterial action against $S$. aureus and $E$. coli bacteria, while they did not show any cytotoxic effect in human dermal fibroblasts (HDFs) even with an AMPs incorporation of $10 \mathrm{mg} / \mathrm{cm}^{2}$ [253]. Another investigation used an antimicrobial peptide PEP-1 incorporated in a conventional PP mesh with large pores and showed adequate in vitro release of the peptide while maintaining a similar tensile strength to two commercial meshes and effective antibacterial activity against E. coli without inducing toxicity in HDFs [254].

\subsection{Meshes produced by combined strategies}

PP meshes coated with triclosan-chitosan revealed a reduction of $S$. aureus adherence to polypropylene grafts in an in vivo rat model [255]. Another study of combined antimicrobial strategies showed that the main body of a laminar mesh of ePTFE with a coating of silver carbonate and chlorhexidine diacetate remained clean but thick fibrous encapsulation, seroma and purulent material were observed related to the mesh anchorage (see Figure 6) [221]. In the same research line, a mesoporous silica nanoplatform (MSN) composed of levofloxacin (Lev) and silver (Lev@MSN@Ag), and poly-L-lactide (PLLA) electrospun (Lev@MSN@AgPLLA) via blending electrospinning was proposed as an alternative antimicrobial option for hernia repair (see Figure 8) [256]. 


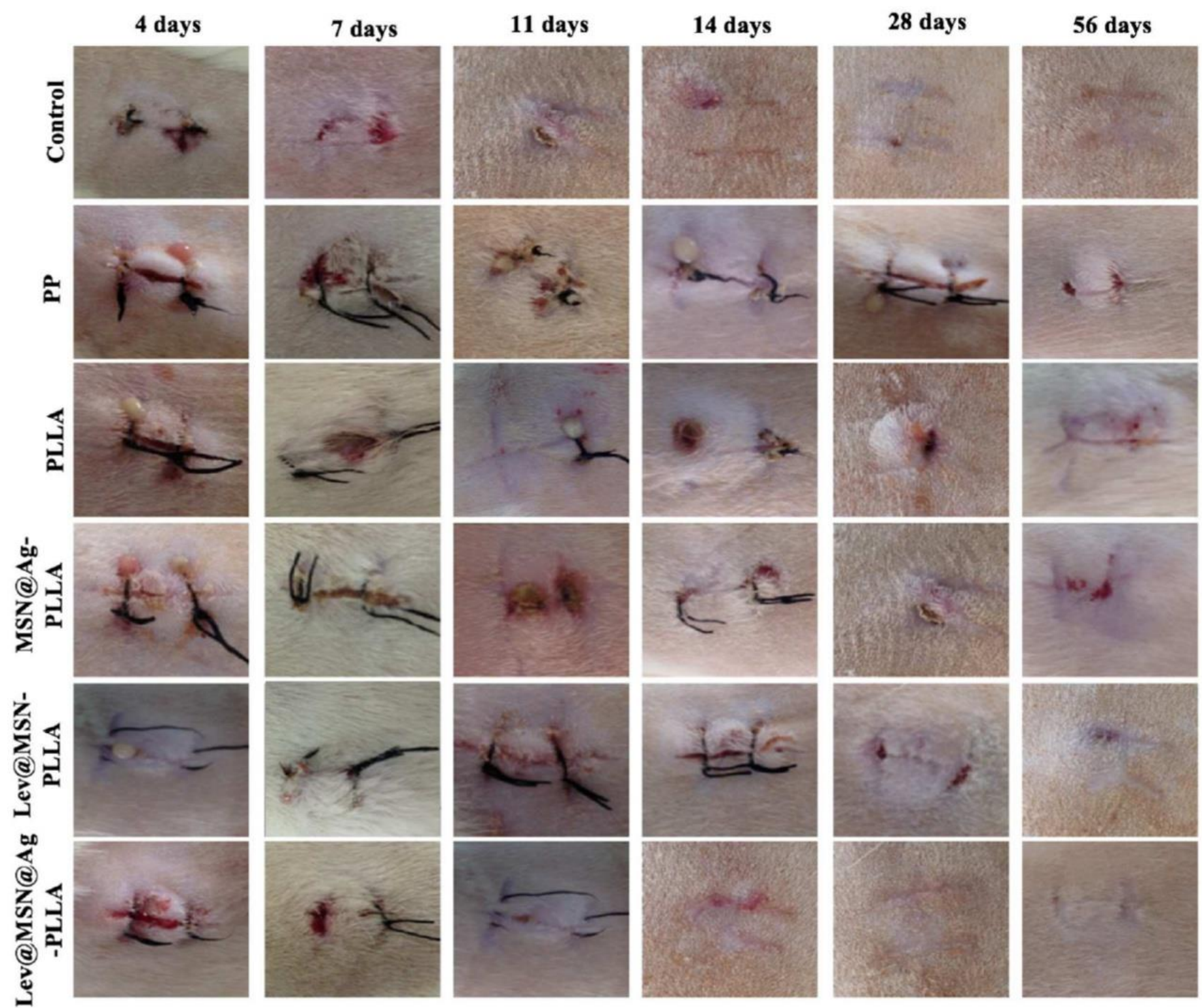

Figure 8. Macroscopic evaluation. Images indicating the wound healing status and scar formation. (a) control, (b) PP, (c) PLLA, (d) MSN@Ag-PLLA, (e)Lev@MSN-PLLA, (f) Lev@MSN@Ag-PLLA - Published by The Royal Society of Chemistry (RSC)[256].

The combined action of these compounds allows high inhibition of resistant bacteria without the need for applying high doses of antibiotics, which can be toxic for the human body. Another strategy for producing antimicrobial meshes consisted of loading electrospun PCL scaffolds with either an antibacterial agent, irgasan, which provides slow release, or a broad-spectrum antibiotic with burst release, levofloxacin [257]. Both advanced meshes were able to inhibit the growth of E. coli and S. aureus by the agar diffusion test [263]. The alginate biopolymer possesses excellent water sorption, biocompatibility, biodegradation, and is a renewable material with a wide range of biomedical applications [264-270]. 3D printed meshes made of PCL containing alginate and gentamicin were recently implanted in rats and showed bactericidal effects and good histopathological behaviour [258]. A multifunctional prosthetic polyester-based hybrid mesh for hernia repair has been developed by using commercial polyester as the backbone material to ensure mechanical integrity, coated with a complex antimicrobial and healing promoting coating made of chitosan with pluronic nanomicelles loaded with phenytoin and microparticles of ciprofloxacin-alginate polyelectrolyte complex [259]. These prostheses possess excellent antimicrobial activity against $S$. aureus and $P$. aeruginosa and efficient healing with excellent biocompatibility was achieved in vivo in dogs. More recently, the coaxial electrospinning technique was investigated in order to develop new core/shell nanofibres with mechanically stable structures consisting of a core made of Nylon-6 and a shell composed of chitosan/polyethylene oxide, which incorporates antimicrobial capacity against $S$. aureus and $P$. aeruginosa by dual drug release of poly (hexanide) from both the shell and the core [260]. The antimicrobial performance and tissue response of the 
PP meshes soaked with chlorhexidine (shown in Figure 6) have recently been improved by cyanoacrylate adhesive fixation [261] (see Figure 9).

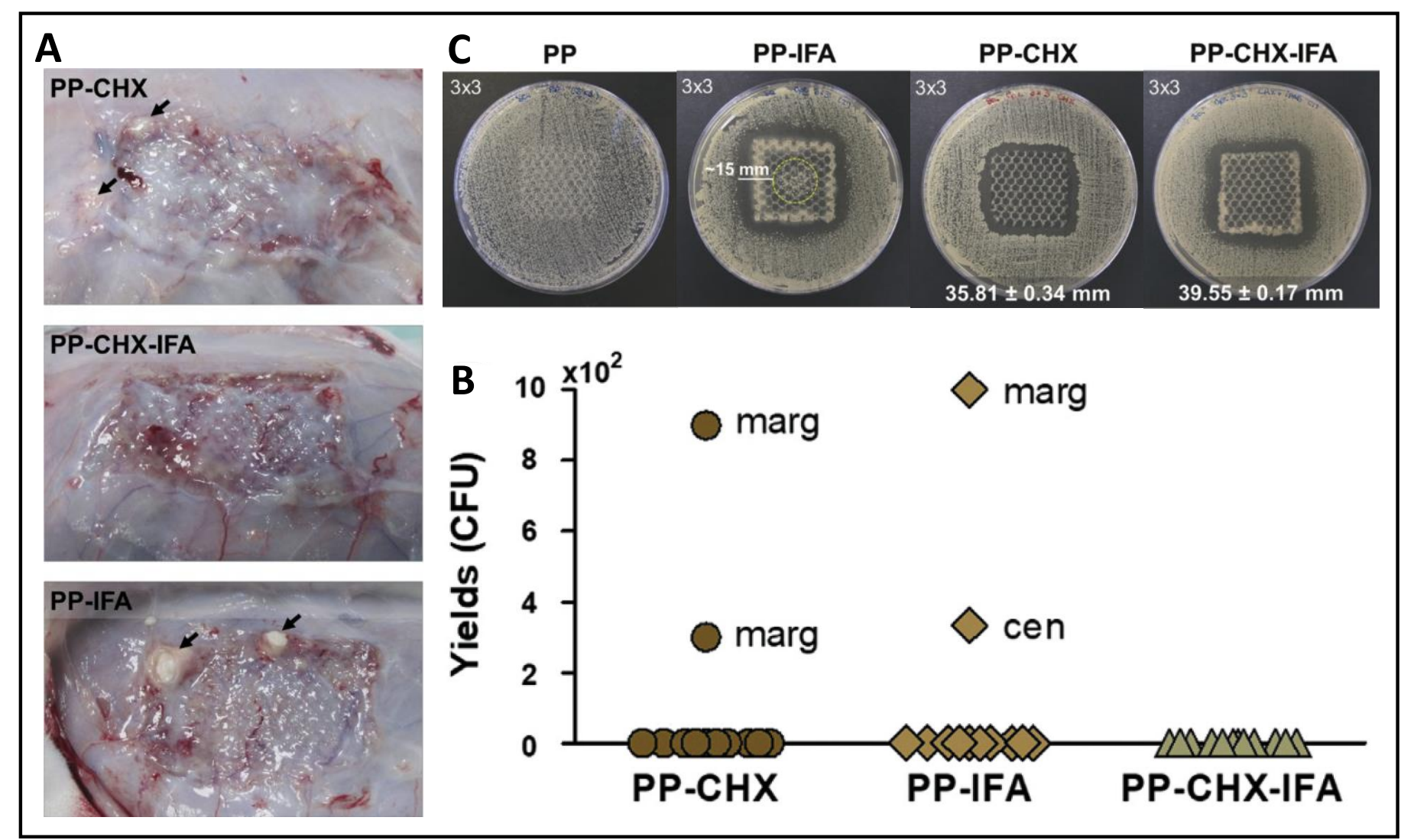

Figure 9. Macroscopic representative images at the time of rabbit euthanasia using PP meshes with chlorhexidine (PP-CHX), PP meshes with chlorhexidine fixed with cyanoacrylate adhesive (PP-CHX-IFA) and PP meshes fixed with cyanoacrylate adhesive (PP-IFA) (A). Purulent material, indicated by black arrows, only appeared on the surface of the PP-CHX and PP-IFA meshes. The bacterial adhesion was quantified (B) and showed no $S$. aureus adhered to the PP-CHX-IFA meshes. However, the PP-CHX and PP-IFA showed $S$. aureus adhesion in the marginal (marg) or central (cen) zones. The growth inhibition effect of the Optilene ${ }^{\circledR}$ meshes (PP), PP-IFA, PP-CHX and PP-CHX-IFA on the growth of S. aureus after more than 24 hours of culture (C). The PP-IFA meshes produced bacterial inhibition zones $15 \mathrm{~mm}$ in diameter (see dashed line). Adapted with permission from Elsevier [261].

This combined strategy of an antibacterial polymer (cyanoacrylate adhesive) [271] with an antiseptic (chlorhexidine) provides an enhanced solution that demonstrated in preclinical studies in a rabbit animal model to be capable of preventing Gram-positive $S$. aureus infections without affecting mesh integration. However, its performance against other clinically relevant bacterial strains and its long-term in vivo evaluation needs to be evaluated. A great deal of further research therefore needs to be performed in order to develop the ideal mesh that fulfils all the optimal requirements for hernia repair, such as good integration to the abdominal wall providing suitable mechanical functionality, low incidence of visceral adhesion, minimal inflammatory or foreign body reaction, and capable of preventing infections, including multidrug-resistant strains.

\section{Conclusions}

Polypropylene mesh is probably the most frequent porous polymer matrix used for hernia repair in clinical practice due to its good physical and biological properties, as well as its reasonable price. However, there are many other alternative options composed of a broad range of biomaterials that can be summarised to facilitate the available options when surgeons have to decide on the type of mesh to be used. The classification of the most important meshes used in clinical practice includes their capacity to be completely bioabsorbed or partially bioabsorbed. The structures of these meshes are also described, indicating whether they are reticular, laminar, hybrid, composite, autoadhesive, biological, biosynthetic or synthetic, with all the information regarding biomaterials, trademarks, tissue integration and capacity to create neoperitoneum. Even though we are still far from producing the ideal antimicrobial mesh for hernia repair, all the progress achieved so far and the advanced antimicrobial meshes developed during the last decade are included in this review. We therefore encourage researchers to keep on working on the development of an optimal mesh capable of providing 
optimal integration to the abdominal wall, mechanical functionality, low visceral adhesion and minimal inflammatory or foreign body reaction, while simultaneously capable of dealing with the life-threatening problem of microbial infections, especially those that are multidrug-resistant.

\section{Abbreviation list}

AMPs
CD
CDC
CMC
cPTFE
ECM
EDAC
ePTFE
FDM
HA
HApN
HDFs
HDI
HMDI
IPOM
Lev
Lev@MSN@Ag
Lev@MSN@Ag-PLLA

MSN

PBS

PBSA

PBSA2- $g-\mathrm{Lv}$

PCL

PDO

PE

PEG

PEGDGE

PET

PGA

PGA-TMC

PGA-PTMC

PHAs

PLA

PLA-PTMC

PLGA

PLGA-PTMC

PLLA

PTFE

PTMC

PVDF

PVP

PP

PU

4PHB

QA

TAPP

TEP
Antimicrobial peptides

$\beta$-Cyclodextrin prepolymer

Centers for Disease Control

Carboxymethylcellulose

Condensated polytetrafluoroethylene

Extracellular matrix

1-ethyl-3- (3-dimethylaminopropyl) carbodiimide hydrochloride

Expanded polytetrafluoroethylene

Fused deposition modelling

Hyaluronic acid

Hyaluronic acid-poly(N-isopropylacrylamide)

Human dermal fibroblasts

Hexamethylene diisocyanate

Hexamethylene diisocyanate

Intraperitoneal onlay mesh

Levofloxacin

Mesoporous silica nanoplatform consisting of levofloxacin and silver

Mesoporous silica nanoplatform consisting of levofloxacin and silver with poly-

L-lactide electrospun membranes

Mesoporous silica nanoplatform

Polybutylene succinate

Poly(butylene succinate-co-butylene aspartate)

Poly(butylene succinate-co-butylene aspartate) with levofloxacin

Poly- $\varepsilon$-caprolactone

Polydioxanone

Polyethylene

Polyethylene glycol

Polyethylene glycol diglycidyl ether

Polyethylene terephthalate

Polyglycolic acid

Polyglycolic acid-trimethylene carbonate

PGA copolymerized with poly(trimethylene carbonate)

Polyhydroxyalkanoates

Polylactic acid

PLA copolymerized with poly(trimethylene carbonate)

Poly(lactic-co-glycolic acid)

PLGA copolymerized with poly(trimethylene carbonate)

Poly-L-lactide

Polytetrafluoroethylene

Poly(trimethylene carbonate)

Polyvinylidene fluoride or polyvinylidene difluoride

Polyvinylpyrrolidone

Polypropylene

Polyurethane

Poly(4-hydroxybutyrate)

Quaternary Ammonium

Transabdominal preperitoneal repair

Total extraperitoneal repair 


\section{Acknowledgments}

The authors are grateful to the Fundación Universidad Católica de Valencia San Vicente Mártir for the financial support through Grants 2019-231-003UCV and 2020-231-006UCV (awarded to Á.S-A).

\section{Conflicts of Interest}

The authors declare no conflict of interest.

\section{References}

[1] M.P. Simons, M. Smietanski, H.J. Bonjer, R. Bittner, M. Miserez, T.J. Aufenacker, R.J. Fitzgibbons, P.K. Chowbey, H.M. Tran, R. Sani, F. Berrevoet, J. Bingener, T. Bisgaard, K. Bury, G. Campanelli, D.C. Chen, J. Conze, D. Cuccurullo, A.C. de Beaux, H.H. Eker, R.H. Fortelny, J.F. Gillion, B.J. van den Heuvel, W.W. Hope, L.N. Jorgensen, U. Klinge, F. Köckerling, J.F. Kukleta, I. Konate, A.L. Liem, D. Lomanto, M.J.A. Loos, M. Lopez-Cano, M.C. Misra, A. Montgomery, S. Morales-Conde, F.E. Muysoms, H. Niebuhr, P. Nordin, M. Pawlak, G.H. van Ramshorst, W.M.J. Reinpold, D.L. Sanders, N. Schouten, S. Smedberg, R.K.J. Simmermacher, S. Tumtavitikul, N. van Veenendaal, D. Weyhe, A.R. Wijsmuller, International guidelines for groin hernia management, Hernia. 22 (2018). https://doi.org/10.1007/s10029-017-1668-X.

[2] D. Lomanto, Hernia Surgery in Asia, in: Art Hernia Surg., Springer International Publishing, 2018 : pp. 123-124. https://doi.org/10.1007/978-3-319-72626-7_12.

[3] Allied Market Research, Hernia Repair Devices and Consumables Market, (2020). https://www.alliedmarketresearch.com/hernia-repair-devices-market (accessed December 28, 2020).

[4] F.E. Muysoms, M. Miserez, F. Berrevoet, G. Campanelli, G.G. Champault, E. Chelala, U.A. Dietz, H.H. Eker, I. El Nakadi, P. Hauters, M. Hidalgo Pascual, A. Hoeferlin, U. Klinge, A. Montgomery, R.K.J. Simmermacher, M.P. Simons, M. Śmietański, C. Sommeling, T. Tollens, T. Vierendeels, A. Kingsnorth, Classification of primary and incisional abdominal wall hernias, Hernia. 13 (2009) 407414. https://doi.org/10.1007/s10029-009-0518-x.

[5] U. Barbaros, O. Asoglu, R. Seven, Y. Erbil, A. Dinccag, U. Deveci, S. Ozarmagan, S. Mercan, The comparison of laparoscopic and open ventral hernia repairs: A prospective randomized study, Hernia. 11 (2007) 51-56. https://doi.org/10.1007/s10029-006-0160-9.

[6] B. Lau, H. Kim, P.I. Haigh, T. Tejirian, Obesity increases the odds of acquiring and incarcerating noninguinal abdominal wall hernias, Am. Surg. 78 (2012) 1118-1121. https://doi.org/10.1177/000313481207801024.

[7] C.E. Ruhl, J.E. Everhart, Risk factors for inguinal hernia among adults in the US population, Am. J. Epidemiol. 165 (2007) 1154-1161. https://doi.org/10.1093/aje/kwm011.

[8] J.W.A. Burger, R.W. Luijendijk, W.C.J. Hop, J.A. Halm, E.G.G. Verdaasdonk, J. Jeekel, T.N. Pappas, C.E. Lucas, C.A. Pellegrini, D.W. Easter, J.E. Fischer, S.J. Mathes, L.W. Way, H.T. Debas, R.S. Jones, Long-term follow-up of a randomized controlled trial of suture versus mesh repair of incisional hernia, Ann. Surg. 240 (2004) 578-585. https://doi.org/10.1097/01.sla.0000141193.08524.e7.

[9] M. Korenkov, S. Sauerland, M. Arndt, L. Bograd, E.A.M. Neugebauer, H. Troidl, Randomized clinical trial of suture repair, polypropylene mesh or autodermal hernioplasty for incisional hernia, $\mathrm{Br}$. J. Surg. 89 (2002) 50-56. https://doi.org/10.1046/j.0007-1323.2001.01974.x.

[10] J. Höer, G. Lawong, U. Klinge, V. Schumpelick, Einflussfaktoren der Narbenhernienentstehung: Retrospektive Untersuchung an 2.983 laparotomierten Patienten über einen Zeitraum von 10 Jahren, Chirurg. 73 (2002) 474-480. https://doi.org/10.1007/s00104-002-0425-5.

[11] A.S. Kashyap, K.P. Anand, S. Kashyap, Inguinal and incisional hernias., Lancet. 363 (2004) 84. 
https://doi.org/10.1016/s0140-6736(03)15211-7.

[12] G. Merola, G. Cavallaro, O. Iorio, M. Frascio, E. Pontecorvi, F. Corcione, J. Andreuccetti, G. Pignata, C. Stabilini, U. Bracale, Learning curve in open inguinal hernia repair: a quality improvement multicentre study about Lichtenstein technique, Hernia. 24 (2020) 651-659. https://doi.org/10.1007/s10029-019-02064-X.

[13] J. Martínez-Hoed, P. García-Pastor, M. Menéndez Jiménez de Zadava Lisson, S. Pous-Serrano, National Survey on the management of inguinal hernia in Spain. Comparison of results with the international guide of The Hernia Surge Group, Rev. Hispanoam. Hernia. (2020). https://doi.org/10.20960/rhh.00345.

[14] S.H. Ein, I. Njere, A. Ein, Six thousand three hundred sixty-one pediatric inguinal hernias: a 35-year review, J. Pediatr. Surg. 41 (2006) 980-986. https://doi.org/10.1016/j.jpedsurg.2006.01.020.

[15] C.S. Olesen, K. Andresen, S. Öberg, J. Rosenberg, Laparoscopic versus open repair of groin hernias in children: a systematic review and meta-analysis, Surg. Endosc. 33 (2019) 2050-2060. https://doi.org/10.1007/s00464-019-06740-y.

[16] L. Tastaldi, D.M. Krpata, A.S. Prabhu, C.C. Petro, R. Ilie, I.N. Haskins, H. Alkhatib, C. Tu, S. Rosenblatt, M.J. Rosen, Emergent groin hernia repair: A single center 10-year experience, Surg. (United States). 165 (2019) 398-405. https://doi.org/10.1016/j.surg.2018.08.001.

[17] J. Burcharth, M. Pedersen, T. Bisgaard, C. Pedersen, J. Rosenberg, Nationwide Prevalence of Groin Hernia Repair, PLoS One. 8 (2013) 1-6. https://doi.org/10.1371/journal.pone.0054367.

[18] K. McCormack, N. Scott, P.M.N.Y.. Go, S.J. Ross, A. Grant, Laparoscopic techniques versus open techniques for inguinal hernia repair, Cochrane Database Syst. Rev. (2003). https://doi.org/10.1002/14651858.cd001785.

[19] R.W. Luijendijk, M.H.M. Lemmen, W.C.J. Hop, J.C.J. Wereldsma, Incisional hernia recurrence following "vest-over-pants" or vertical mayo repair of primary hernias of the midline, World J. Surg. 21 (1997) 62-66. https://doi.org/10.1007/s002689900194.

[20] D. Abelló, J. Martínez-Hoed, M. Menéndez, H. Cholewa, L. Avelino, S. Bonafé, S. Pous-Serrano, J. Bueno-Lledo, Comparative analysis of 2 surgical techniques in the treatment of subxiphoid incisional hernia. Observational study, Cir. Esp. (2020). https://doi.org/10.1016/j.ciresp.2020.08.014.

[21] S. Pous-Serrano, Clinical practice guidelines in surgery: are really useful?, Rev. Hispanoam. Hernia. (2020). https://doi.org/10.20960/rhh.00376.

[22] K.M.F. Itani, L. Neumayer, D. Reda, L. Kim, T. Anthony, Repair of ventral incisional hernia: The design of a randomized trial to compare open and laparoscopic surgical techniques, Am. J. Surg. 188 (2004) 22-29. https://doi.org/10.1016/j.amjsurg.2004.09.006.

[23] W.W. Vrijland, J. Jeekel, E.W. Steyerberg, P.T. Den Hoed, H.J. Bonjer, Intraperitoneal polypropylene mesh repair of incisional hernia is not associated with enterocutaneous fistula, Br. J. Surg. 87 (2000) 348-352. https://doi.org/10.1046/j.1365-2168.2000.01364.x.

[24] S.S. Awad, S.P. Fagan, Current approaches to inguinal hernia repair, Am. J. Surg. 188 (2004) 9-16. https://doi.org/10.1016/j.amjsurg.2004.09.007.

[25] S.S. Awad, S. Yallalampalli, A.M. Srour, C.F. Bellows, D. Albo, D.H. Berger, Improved outcomes with the Prolene Hernia System mesh compared with the time-honored Lichtenstein onlay mesh repair for inguinal hernia repair, Am. J. Surg. 193 (2007) 697-701.

https://doi.org/10.1016/j.amjsurg.2006.08.087.

[26] J. Zieren, B. Hoksch, F.A. Wenger, I. Opitz, J.M. Müller, Inguinal hernia repair in the new millennium: Plug and patch repair with local anesthesia, World J. Surg. 25 (2001) 138-141. https://doi.org/10.1007/s002680020093.

[27] A.N. Kingsnorth, C.S. Porter, D.H. Bennett, A.J. Walker, M.E. Hyland, S. Sodergren, Lichtenstein patch or Perfix plug-and-patch in inguinal hernia: A prospective double-blind randomized controlled trial of short-term outcome, Surgery. 127 (2000) 276-283. https://doi.org/10.1067/msy.2000.104124.

[28] R.D. Kugel, Minimally invasive, nonlaparoscopic, preperitoneal, and sutureless, inguinal herniorrhaphy, Am. J. Surg. 178 (1999) 298-302. https://doi.org/10.1016/S0002-9610(99)00181-6.

[29] R.D. Kugel, The Kugel repair for groin hernias, Surg. Clin. North Am. 83 (2003) 1119-1139. https://doi.org/10.1016/S0039-6109(03)00123-3.

[30] R. Bittner, M.A. Montgomery, E. Arregui, V. Bansal, J. Bingener, T. Bisgaard, H. Buhck, M. Dudai, G.S. Ferzli, R.J. Fitzgibbons, R.H. Fortelny, K.L. Grimes, U. Klinge, F. Koeckerling, S. Kumar, J. 
Kukleta, D. Lomanto, M.C. Misra, S. Morales-Conde, W. Reinpold, J. Rosenberg, K. Singh, M. Timoney, D. Weyhe, P. Chowbey, Update of guidelines on laparoscopic (TAPP) and endoscopic (TEP) treatment of inguinal hernia (International Endohernia Society), Surg. Endosc. 29 (2015) 289321. https://doi.org/10.1007/s00464-014-3917-8.

[31] R.S. Chung, D.Y. Rowland, Meta-analyses of randomized controlled trials of laparoscopic vs conventional inguinal hernia repairs, Surg. Endosc. 13 (1999) 689-694. https://doi.org/10.1007/s004649901074.

[32] C.J. Davis, M.E. Arregui, Laparoscopic repair for groin hernias, Surg. Clin. North Am. 83 (2003) 1141-1161. https://doi.org/10.1016/S0039-6109(03)00122-1.

[33] A. Verbo, P. Pafundi, A. Manno, R. Bacccaro, A. Veneziani, R. Colli, C. Coco, Polyvinylidene Fluoride Mesh (PVDF, DynaMesh®-IPOM) in The Laparoscopic Treatment of Incisional Hernia: A Prospective Comparative Trial versus Gore ${ }^{\circledR}$ ePTFE DUALMESH® Plus, Surg. Technol. Int. 28 (2016) 147-151.

[34] N.A. Henriksen, A. Montgomery, R. Kaufmann, F. Berrevoet, B. East, J. Fischer, W. Hope, D. Klassen, R. Lorenz, Y. Renard, M.A. Garcia Urena, M.P. Simons, Guidelines for treatment of umbilical and epigastric hernias from the European Hernia Society and Americas Hernia Society, Br. J. Surg. 107 (2020) 171-190. https://doi.org/10.1002/bjs.11489.

[35] J. Bueno-Lledó, J. Martinez-Hoed, A. Torregrosa-Gallud, M. Menéndez-Jiménez, S. Pous-Serrano, Botulinum toxin to avoid component separation in midline large hernias, Surg. (United States). 168 (2020) 543-549. https://doi.org/10.1016/j.surg.2020.04.050.

[36] J. Bueno-Lledó, O. Carreño-Saenz, A. Torregrosa-Gallud, S. Pous-Serrano, Preoperative Botulinum Toxin and Progressive Pneumoperitoneum in Loss of Domain Hernias-Our First 100 Cases, Front. Surg. 7 (2020) 3. https://doi.org/10.3389/fsurg.2020.00003.

[37] S. Kalaba, E. Gerhard, J.S. Winder, E.M. Pauli, R.S. Haluck, J. Yang, Design strategies and applications of biomaterials and devices for Hernia repair, Bioact. Mater. 1 (2016) 2-17. https://doi.org/10.1016/j.bioactmat.2016.05.002.

[38] J.R. Asarias, P.T. Nguyen, J.R. Mings, A.P. Gehrich, L.M. Pierce, Influence of mesh materials on the expression of mediators involved in wound healing, J. Investig. Surg. 24 (2011) 87-98. https://doi.org/10.3109/08941939.2010.548904.

[39] U. Klinge, B. Klosterhalfen, M. Müller, V. Schumpelick, Foreign body reaction to meshes used for the repair of abdominal wall hernias, Eur. J. Surg. 165 (1999) 665-673. https://doi.org/10.1080/11024159950189726.

[40] S.B. Orenstein, Y. Qiao, M. Kaur, U. Klueh, D.L. Kreutzer, Y.W. Novitsky, Human monocyte activation by biologic and biodegradable meshes in vitro, Surg. Endosc. 24 (2010) 805-811. https://doi.org/10.1007/s00464-009-0664-3.

[41] C.J. Brandt, D. Kammer, A. Fiebeler, U. Klinge, Beneficial effects of hydrocortisone or spironolactone coating on foreign body response to mesh biomaterial in a mouse model, J. Biomed. Mater. Res. - Part A. 99 A (2011) 335-343. https://doi.org/10.1002/jbm.a.33136.

[42] A. Contreras-García, C. Alvarez-Lorenzo, C. Taboada, A. Concheiro, E. Bucio, Stimuli-responsive networks grafted onto polypropylene for the sustained delivery of NSAIDs, Acta Biomater. 7 (2011) 996-1008. https://doi.org/10.1016/j.actbio.2010.10.001.

[43] C. Hu, S. Liu, Y. Zhang, B. Li, H. Yang, C. Fan, W. Cui, Long-term drug release from electrospun fibers for in vivo inflammation prevention in the prevention of peritendinous adhesions, Acta Biomater. 9 (2013) 7381-7388. https://doi.org/10.1016/j.actbio.2013.03.040.

[44] J.C. Tharappel, C.E. Bower, J. Whittington Harris, S.K. Ramineni, D.A. Puleo, J.S. Roth, Doxycycline administration improves fascial interface in hernia repair, J. Surg. Res. 190 (2014) 692698. https://doi.org/10.1016/j.jss.2014.05.013.

[45] K. Junge, R. Rosch, M. Anurov, S. Titkova, A. Öttinger, U. Klinge, V. Schumpelick, Modification of collagen formation using supplemented mesh materials, Hernia. 10 (2006) 492-497. https://doi.org/10.1007/s10029-006-0148-5.

[46] W. Zimmerli, Prosthetic-joint-associated infections, Best Pract. Res. Clin. Rheumatol. 20 (2006) 1045-1063. https://doi.org/10.1016/j.berh.2006.08.003.

[47] B. Klosterhalfen, U. Klinge, B. Hermanns, V. Schumpelick, Pathologie traditioneller chirurgischer Netze zur Hernienreparation nach Langzeitimplantation im Menschen, Chirurg. 71 (2000) 43-51. 
https://doi.org/10.1007/s001040050007.

[48] O. Langbach, A.K. Kristoffersen, E. Abesha-Belay, M. Enersen, O. Røkke, I. Olsen, Oral, intestinal, and skin bacteria in ventral hernia mesh implants, J. Oral Microbiol. 8 (2016). https://doi.org/10.3402/jom.v8.31854.

[49] L. Yang, H. Wang, X. Liang, T. Chen, W. Chen, Y. Song, J. Wang, Bacteria in hernia sac: an important risk fact for surgical site infection after incarcerated hernia repair, Hernia. 19 (2015) 279283. https://doi.org/10.1007/s10029-014-1275-z.

[50] M. Musella, A. Guido, S. Musella, Collagen tampons as aminoglycoside carriers to reduce postoperative infection rate in prosthetic repair of groin hernias, Eur. J. Surg. 167 (2001) 130-132. https://doi.org/10.1080/110241501750070592.

[51] O. Guillaume, R. Pérez-Tanoira, R. Fortelny, H. Redl, T.F. Moriarty, R.G. Richards, D. Eglin, A. Petter Puchner, Infections associated with mesh repairs of abdominal wall hernias: Are antimicrobial biomaterials the longed-for solution?, Biomaterials. 167 (2018) 15-31.

https://doi.org/10.1016/j.biomaterials.2018.03.017.

[52] WHO | Antimicrobial resistance: global report on surveillance 2014, World Health Organization, 2016.

[53] N. Scott, G. Pm, P. Graham, K. Mccormack, R. Sj, G. Am, Open Mesh versus non-Mesh for groin hernia repair ( Review ), (2011). https://doi.org/10.1002/14651858.CD002197.www.cochranelibrary.com.

[54] G. Welty, U. Klinge, B. Klosterhalfen, R. Kasperk, V. Schumpelick, Functional impairment and complaints following incisional hernia repair with different polypropylene meshes, Hernia. 5 (2001) 142-147. https://doi.org/10.1007/s100290100017.

[55] D. Weyhe, O. Belyaev, C. Müller, K. Meurer, K.H. Bauer, G. Papapostolou, W. Uhl, Improving outcomes in hernia repair by the use of light meshes - A comparison of different implant constructions based on a critical appraisal of the literature, World J. Surg. 31 (2007) 234-244. https://doi.org/10.1007/s00268-006-0123-4.

[56] V. Schumpelick, U. Klinge, K. Junge, M. Stumpf, Incisional abdominal hernia: The open mesh repair, Langenbeck's Arch. Surg. 389 (2004) 1-5. https://doi.org/10.1007/s00423-003-0352-z.

[57] A.N. Kingsnorth, N. Sivarajasingham, S. Wong, M. Butler, Open mesh repair of incisional hernias with significant loss of domain, Ann. R. Coll. Surg. Engl. 86 (2004) 363-366. https://doi.org/10.1308/147870804236.

[58] C. Langer, T. Neufang, C. Kley, Aktuelle Operationstechnik Standardisierte Polypropylennetzplastik der Narbenhernie in Sublay-Technik, Delta. (2001).

[59] J. Conze, C.J. Krones, V. Schumpelick, U. Klinge, Incisional hernia: Challenge of re-operations after mesh repair, Langenbeck's Arch. Surg. 392 (2007) 453-457. https://doi.org/10.1007/s00423-0060065-1.

[60] M.R. Bruins, S. Kapil, F.W. Oehme, Microbial resistance to metals in the environment, Ecotoxicol. Environ. Saf. 45 (2000) 198-207. https://doi.org/10.1006/eesa.1999.1860.

[61] P.K. Amid, Classification of biomaterials and their related complications in abdominal wall hernia surgery, Hernia. 1 (1997) 15-21. https://doi.org/10.1007/bf02426382.

[62] U. Klinge, B. Klosterhalfen, Modified classiffication of surgical meshes for hernia repair based on the analyses of 1,000 explanted meshes, Hernia. 16 (2012) 251-258. https://doi.org/10.1007/s10029-0120913-6.

[63] J.M. Bellón, Revisión de una clasificación de materiales protésicos destinados a la reparación herniaria: correlación entre estructura y comportamiento en los tejidos receptores, Rev. Hispanoam. Hernia. 2 (2014) 49-57. https://doi.org/10.1016/j.rehah.2014.02.002.

[64] V. Gómez-Gil, M. Rodríguez, F. García-Moreno Nisa, B. Pérez-Köhler, G. Pascual, Evaluation of synthetic reticular hybrid meshes designed for intraperitoneal abdominal wall repair: Preclinical and in vitro behavior, PLoS One. 14 (2019) e0213005. https://doi.org/10.1371/journal.pone.0213005.

[65] M. Affolter, R. Zeller, E. Caussinus, Tissue remodelling through branching morphogenesis, Nat. Rev. Mol. Cell Biol. 10 (2009) 831-842. https://doi.org/10.1038/nrm2797.

[66] J.M. Ferrando, J. Vidal, M. Armengol, J. Gil, J.M. Manero, P. Huguet, A. Segarra, M.T. Quiles, S. Schwartz, M.A. Arbós i Via, Experimental evaluation of a new layered prosthesis exhibiting a low tensile modulus of elasticity: Long-term integration response within the rat abdominal wall, World J. 
Surg. 26 (2002) 409-415. https://doi.org/10.1007/s00268-001-0240-z.

[67] G. Pascual, C. Mesa-Ciller, M. Rodríguez, B. Pérez-Köhler, V. Gómez-Gil, M. Fernández-Gutiérrez, J.S. Román, J.M. Bellón, Pre-clinical assay of the tissue integration and mechanical adhesion of several types of cyanoacrylate adhesives in the fixation of lightweight polypropylene meshes for abdominal hernia repair, PLoS One. 13 (2018). https://doi.org/10.1371/journal.pone.0206515.

[68] J.M. Bellón, F. Jurado, N. García-Honduvilla, R. López, A. Carrera-San Martín, J. Buján, The structure of a biomaterial rather than its chemical composition modulates the repair process at the peritoneal level, Am. J. Surg. 184 (2002) 154-159. https://doi.org/10.1016/S0002-9610(02)00907-8.

[69] B.D. Matthews, B.L. Pratt, H.S. Pollinger, C.L. Backus, K.W. Kercher, R.F. Sing, B.T. Heniford, Assessment of adhesion formation to intra-abdominal polypropylene mesh and polytetrafluoroethylene mesh, J. Surg. Res. 114 (2003) 126-132. https://doi.org/10.1016/S00224804(03)00158-6.

[70] D.B. Earle, L.A. Mark, Prosthetic Material in Inguinal Hernia Repair: How Do I Choose?, Surg. Clin. North Am. 88 (2008) 179-201. https://doi.org/10.1016/j.suc.2007.11.002.

[71] Y. Bilsel, I. Abci, The search for ideal hernia repair; mesh materials and types, Int. J. Surg. 10 (2012) 317-321. https://doi.org/10.1016/j.ijsu.2012.05.002.

[72] U. Klinge, B. Klosterhalfen, V. Birkenhauer, K. Junge, J. Conze, V. Schumpelick, Impact of polymer pore size on the interface scar formation in a rat model, J. Surg. Res. 103 (2002) 208-214. https://doi.org/10.1006/jsre.2002.6358.

[73] D.F. Taylor, F.B. Smith, Porous methyl methacrylate as an implant material, J. Biomed. Mater. Res. 6 (1972) 467-479. https://doi.org/10.1002/jbm.820060112.

[74] Y.W. Novitsky, A.G. Harrell, J.A. Cristiano, B.L. Paton, H.J. Norton, R.D. Peindl, K.W. Kercher, B.T. Heniford, Comparative Evaluation of Adhesion Formation, Strength of Ingrowth, and Textile Properties of Prosthetic Meshes After Long-Term Intra-Abdominal Implantation in a Rabbit, J. Surg. Res. 140 (2007) 6-11. https://doi.org/10.1016/j.jss.2006.09.015.

[75] K. Junge, U. Klinge, R. Rosch, B. Klosterhalfen, V. Schumpelick, Functional and morphologic properties of a modified mesh for inguinal hernia repair, World J. Surg. 26 (2002) 1472-1480. https://doi.org/10.1007/s00268-002-6444-z.

[76] H.S. Goldstein, Selecting the right mesh, Hernia. 3 (1999) 23-26. https://doi.org/10.1007/BF01576737.

[77] V. Schumpelick, U. Klinge, R. Rosch, K. Junge, Light weight meshes in incisional hernia repair, in: J. Minim. Access Surg., Medknow Publications and Media Pvt. Ltd, 2006: pp. 117-123. https://doi.org/10.4103/0972-9941.27722.

[78] K. Baylón, P. Rodríguez-Camarillo, A. Elías-Zúñiga, J.A. Díaz-Elizondo, R. Gilkerson, K. Lozano, Past, present and future of surgical meshes: A review, Membranes (Basel). 7 (2017). https://doi.org/10.3390/membranes7030047.

[79] M. Monleón-Pradas, J.L. Gómez-Ribelles, Á. Serrano-Aroca, G. Gallego-Ferrer, J. Suay-Antón, P. Pissis, Porous poly(2-hydroxyethyl acrylate) hydrogels, Polymer (Guildf). 42 (2001) 4667-4674. https://doi.org/10.1016/S0032-3861(00)00742-4.

[80] Á. Serrano-Aroca, M. Monleón-Pradas, J.L. Gómez-Ribelles, Macroporous poly(methyl methacrylate) produced by phase separation during polymerisation in solution, Colloid Polym. Sci. 285 (2007) 753-760.

[81] Á. Serrano-Aroca, M. Llorens-Gámez, Dynamic mechanical analysis and water vapour sorption of highly porous poly(methyl methacrylate), Polymer (Guildf). 125 (2017) 58-65. https://doi.org/10.1016/j.polymer.2017.07.075.

[82] A. Serrano Aroca, A.J. Campillo Fernández, J.L. Gómez Ribelles, M. Monleón Pradas, G. Gallego Ferrer, P. Pissis, Porous poly(2-hydroxyethyl acrylate) hydrogels prepared by radical polymerisation with methanol as diluent, Polymer (Guildf). 45 (2004). https://doi.org/10.1016/j.polymer.2004.10.033.

[83] A.S. Aroca, M.M. Pradas, J.L.G. Ribelles, Effect of crosslinking on porous poly(methyl methacrylate) produced by phase separation, Colloid Polym. Sci. 286 (2008) 209-216. https://doi.org/10.1007/s00396-007-1755-0.

[84] J.C. Rodríguez-Hernández, Á. Serrano-Aroca, J.L. Gómez-Ribelles, M. Monleón-Pradas, Threedimensional nanocomposite scaffolds with ordered cylindrical orthogonal pores, J. Biomed. Mater. Res. - Part B Appl. Biomater. 84 (2008) 541-549. 
[85] R. Brígido-Diego, M. Pérez-Olmedilla, Á. Serrano-Aroca, J.L. Gómez-Ribelles, M. Monleón-Pradas, G. Gallego-Ferrer, M. Salmerón-Sánchez, Acrylic scaffolds with interconnected spherical pores and controlled hydrophilicity for tissue engineering, J. Mater. Sci. Mater. Med. 40 (2005) 4881-4887. https://doi.org/10.1007/s10853-005-3885-4.

[86] N. Wang, Z. Zhou, L. Xia, Y. Dai, H. Liu, Fabrication and characterization of bioactive $\beta$ Ca2SiO4/PHBV composite scaffolds, Mater. Sci. Eng. C. 33 (2013) 2294-2301. https://doi.org/10.1016/j.msec.2013.01.059.

[87] G.C. Ebersole, E.G. Buettmann, M.R. MacEwan, M.E. Tang, M.M. Frisella, B.D. Matthews, C.R. Deeken, Development of novel electrospun absorbable polycaprolactone (PCL) scaffolds for hernia repair applications, Surg. Endosc. 26 (2012) 2717-2728. https://doi.org/10.1007/s00464-012-2258-8.

[88] B. Veleirinho, D.S. Coelho, P.F. Dias, M. Maraschin, R. Pinto, E. Cargnin-Ferreira, A. Peixoto, J.A. Souza, R.M. Ribeiro-Do-Valle, J.A. Lopes-Da-Silva, Foreign body reaction associated with PET and PET/chitosan electrospun nanofibrous abdominal meshes, PLoS One. 9 (2014) e95293. https://doi.org/10.1371/journal.pone.0095293.

[89] R. Rynkevic, P. Martins, A. Fernandes, J. Vange, M.R. Gallego, R.A. Wach, T. Mes, A.W. Bosman, J. Deprest, In vitro simulation of in vivo degradation and cyclic loading of novel degradable electrospun meshes for prolapse repair, Polym. Test. 78 (2019) 105957. https://doi.org/10.1016/j.polymertesting.2019.105957.

[90] N. Qamar, N. Abbas, M. Irfan, A. Hussain, M.S. Arshad, S. Latif, F. Mehmood, M.U. Ghori, Personalized 3D printed ciprofloxacin impregnated meshes for the management of hernia, J. Drug Deliv. Sci. Technol. 53 (2019) 101164. https://doi.org/10.1016/j.jddst.2019.101164.

[91] D.H. Ballard, U. Jammalamadaka, K. Tappa, J.A. Weisman, C.J. Boyer, J.S. Alexander, P.K. Woodard, 3D printing of surgical hernia meshes impregnated with contrast agents: in vitro proof of concept with imaging characteristics on computed tomography, 3D Print. Med. 4 (2018) 1-6. https://doi.org/10.1186/s41205-018-0037-4.

[92] D.H. Ballard, J.A. Weisman, U. Jammalamadaka, K. Tappa, J.S. Alexander, F.D. Griffen, Threedimensional printing of bioactive hernia meshes: In vitro proof of principle, Surg. (United States). 161 (2017) 1479-1481. https://doi.org/10.1016/j.surg.2016.08.033.

[93] C. Schug-Pass, H. Lippert, F. Köckerling, Mesh fixation with fibrin glue (Tissucol/Tisseel®) in hernia repair dependent on the mesh structure - Is there an optimum fibrin-mesh combination? Investigations on a biomechanical model, Langenbeck's Arch. Surg. 395 (2010) 569-574. https://doi.org/10.1007/s00423-009-0466-z.

[94] S. Todros, P.G. Pavan, A.N. Natali, Synthetic surgical meshes used in abdominal wall surgery: Part I-materials and structural conformation, J. Biomed. Mater. Res. - Part B Appl. Biomater. 105 (2017) 689-699. https://doi.org/10.1002/jbm.b.33586.

[95] A. Coda, R. Lamberti, S. Martorana, Classification of prosthetics used in hernia repair based on weight and biomaterial, Hernia. 16 (2012) 9-20. https://doi.org/10.1007/s10029-011-0868-z.

[96] G. Pascual, M. Rodríguez, V. Gomez-Gil, N. García-Honduvilla, J. Buján, J.M. Bellón, Early tissue incorporation and collagen deposition in lightweight polypropylene meshes: bioassay in an experimental model of ventral hernia, Surgery. 144 (2008) 427-435. https://doi.org/10.1016/j.surg.2008.04.005.

[97] R.A. Cortes, E. Miranda, H. Lee, M.E. Gertner, Biomaterials and the evolution of hernia repair II: Composite meshes, in: Surg. Basic Sci. Clin. Evid. Second Ed., Springer New York, 2008: pp. 23052315. https://doi.org/10.1007/978-0-387-68113-9_112.

[98] R. Balsamo, E. Illiano, A. Zucchi, F. Natale, A. Carbone, M. De Sio, E. Costantini, Sacrocolpopexy with polyvinylidene fluoride mesh for pelvic organ prolapse: Mid term comparative outcomes with polypropylene mesh, Eur. J. Obstet. Gynecol. Reprod. Biol. 220 (2018) 74-78. https://doi.org/10.1016/j.ejogrb.2017.11.018.

[99] U. Klinge, B. Klosterhalfen, A.P. Öttinger, K. Junge, V. Schumpelick, PVDF as a new polymer for the construction of surgical meshes, Biomaterials. 23 (2002) 3487-3493. https://doi.org/10.1016/S0142-9612(02)00070-4.

[100] A. Jamry, M. Jałyński, J. Śmigielski, M. Brocki, Shrinkage of Dynamesh IPOM mesh in 6-week follow-up - An experimental study, Wideochirurgia I Inne Tech. Maloinwazyjne. 6 (2011) 19-23. https://doi.org/10.5114/wiitm.2011.20988. 
[101] M.R. Langenbach, S. Sauerland, Polypropylene versus Polyester Mesh for Laparoscopic Inguinal Hernia Repair: Short-Term Results of a Comparative Study, Surg. Sci. 04 (2013) 29-34. https://doi.org/10.4236/ss.2013.41005.

[102] S.B. Orenstein, E.R. Saberski, D.L. Kreutzer, Y.W. Novitsky, Comparative analysis of histopathologic effects of synthetic meshes based on material, weight, and pore size in mice, J. Surg. Res. 176 (2012) 423-429. https://doi.org/10.1016/j.jss.2011.09.031.

[103] F. Köckerling, C. Schug-Pass, What do we know about titanized polypropylene meshes? An evidence-based review of the literature, Hernia. 18 (2014) 445-457. https://doi.org/10.1007/s10029013-1187-3.

[104] H.G. Doctor, Evaluation of various prosthetic materials and newer meshes for hernia repairs, in: J. Minim. Access Surg., Medknow Publications and Media Pvt. Ltd, 2006: pp. 110-116. https://doi.org/10.4103/0972-9941.27721.

[105] G. Voskerician, J. Jin, M.F. White, C.P. Williams, M.J. Rosen, Effect of biomaterial design criteria on the performance of surgical meshes for abdominal hernia repair: A pre-clinical evaluation in a chronic rat model, J. Mater. Sci. Mater. Med. 21 (2010) 1989-1995. https://doi.org/10.1007/s10856-0104037-1.

[106] B. Klosterhalfen, K. Junge, U. Klinge, The lightweight and large porous mesh concept for hernia repair, Expert Rev. Med. Devices. 2 (2005) 103-117. https://doi.org/10.1586/17434440.2.1.103.

[107] A. Bako, R. Dhar, Review of synthetic mesh-related complications in pelvic floor reconstructive surgery, Int. Urogynecol. J. 20 (2009) 103-111. https://doi.org/10.1007/s00192-008-0717-5.

[108] E. Bresnahan, A. Bates, A. Wu, M. Reiner, B. Jacob, The use of self-gripping (Progrip ${ }^{\mathrm{TM}}$ ) mesh during laparoscopic total extraperitoneal (TEP) inguinal hernia repair: a prospective feasibility and long-term outcomes study, Surg. Endosc. 29 (2015) 2690-2696. https://doi.org/10.1007/s00464-0143991-y.

[109] K. Rönkä, J. Vironen, J. Kössi, T. Hulmi, S. Silvasti, T. Hakala, I. Ilves, I. Song, M. Hertsi, P. Juvonen, H. Paajanen, Randomized multicenter trial comparing glue fixation, self-gripping mesh, and suture fixation of mesh in lichtenstein hernia repair (FinnMesh Study), Ann. Surg. 262 (2015) 714720. https://doi.org/10.1097/SLA.0000000000001458.

[110] B. Aghaei-Ghareh-Bolagh, S.M. Mithieux, M.A. Hiob, Y. Wang, A. Chong, A.S. Weiss, Fabricated tropoelastin-silk yarns and woven textiles for diverse tissue engineering applications, Acta Biomater. 91 (2019) 112-122. https://doi.org/10.1016/j.actbio.2019.04.029.

[111] O. Guillaume, J. Park, X. Monforte, S. Gruber-Blum, H. Redl, A. Petter-Puchner, A.H. Teuschl, Fabrication of silk mesh with enhanced cytocompatibility: preliminary in vitro investigation toward cell-based therapy for hernia repair, J. Mater. Sci. Mater. Med. 27 (2016) 1-13. https://doi.org/10.1007/s10856-015-5648-3.

[112] D.P. Martin, A. Badhwar, D. V. Shah, S. Rizk, S.N. Eldridge, D.H. Gagne, A. Ganatra, R.E. Darois, S.F. Williams, H.C. Tai, J.R. Scott, Characterization of poly-4-hydroxybutyrate mesh for hernia repair applications, J. Surg. Res. 184 (2013) 766-773. https://doi.org/10.1016/j.jss.2013.03.044.

[113] U. Klinge, V. Schumpelick, B. Klosterhalfen, Functional assessment and tissue response of short- and long-term absorbable surgical meshes, Biomaterials. 22 (2001) 1415-1424. https://doi.org/10.1016/S0142-9612(00)00299-4.

[114] M.A.R.S.H.H. Truong, J.P.M.J. V Brown, I.I.I.B.H. Goldstein, Marlex mesh mimicking an adnexal malignancy, 2007 (2009) 221-223. https://doi.org/10.1007/s10029-008-0426-5.

[115] E. Pikoulis, P. Daskalakis, N. Psallidas, I. Karavokyros, A. Stathoulopolos, D. Godevenos, A. Leppaniemi, P. Tsatsoulis, Marlex Mesh Prefix Plug Hernioplasty Retrospective Analysis of 865 Operations, 234 (2005) 231-234. https://doi.org/10.1007/s00268-005-7548-z.

[116] D.A. Jacob, C. Schug-Paß, F. Sommerer, A. Tannapfel, H. Lippert, F. Köckerling, Comparison of a lightweight polypropylene mesh (Optilene ${ }^{\circledR}$ LP) and a large-pore knitted PTFE mesh (GORE® INFINIT® mesh) - Biocompatibility in a standardized endoscopic extraperitoneal hernia model, Langenbeck's Arch. Surg. 397 (2012) 283-289. https://doi.org/10.1007/s00423-011-0858-8.

[117] D. Berger, M. Bientzle, Polyvinylidene fluoride: A suitable mesh material for laparoscopic incisional and parastomal hernia repair!, Hernia. 13 (2009) 167-172. https://doi.org/10.1007/s10029-008-04354.

[118] D. Berger, Evidence-Based Hernia Treatment in Adults, Dtsch. Arztebl. Int. 113 (2016) 339-346. 
https://doi.org/10.3238/arztebl.2016.0150.

[119] A. Tandon, K. Shahzad, S. Pathak, C.M. Oommen, Q.M. Nunes, N. Smart, Parietex ${ }^{\text {TM }}$ Composite mesh versus DynaMesh®-IPOM for laparoscopic incisional and ventral hernia repair: A retrospective cohort study, Ann. R. Coll. Surg. Engl. 98 (2016) 568-573. https://doi.org/10.1308/rcsann.2016.0292.

[120] A. Vereczkei, G. Varga, T. Tornoczky, A. Papp, Ö.P. Horvath, A new experimental method for hiatal reinforcement using connective tissue patch transfer, Dis. Esophagus. 25 (2012) 465-469. https://doi.org/10.1111/j.1442-2050.2011.01265.x.

[121] B. Ramshaw, F. Abiad, G. Voeller, R. Wilson, E. Mason, Polyester (Parietex) mesh for total extraperitoneal laparoscopic inguinal hernia repair: Initial experience in the United States, Surg. Endosc. Other Interv. Tech. 17 (2003) 498-501. https://doi.org/10.1007/s00464-002-8848-0.

[122] E. Nergiz Adıgüzel, E. Esen, G. Aylaz, B. Keskinkılıç Yağız, M. Kıyan, A. Doğan, A.E. Ünal, Do Nano-crystalline Silver-Coated Hernia Grafts Reduce Infection?, World J. Surg. 42 (2018) 35373542. https://doi.org/10.1007/s00268-018-4661-3.

[123] T. Aura, E. Habib, M. Mekkaoui, D. Brassier, A. Elhadad, Laparoscopic tension-free repair of anterior abdominal wall incisional and ventral hernias with an intraperitoneal Gore-Tex ${ }^{\circledR}$ mesh: Prospective study and review of the literature, J. Laparoendosc. Adv. Surg. Tech. - Part A. 12 (2002) 263-267. https://doi.org/10.1089/109264202760268041.

[124] L.L.Q. Pu, Small intestinal submucosa (Surgisis) as a bioactive prosthetic material for repair of abdominal wall fascial defect, Plast. Reconstr. Surg. 115 (2005) 2127-2131. https://doi.org/10.1097/01.PRS.0000168883.65715.2F.

[125] E.J. Grethel, R.A. Cortes, A.J. Wagner, M.S. Clifton, H. Lee, D.L. Farmer, M.R. Harrison, R.L. Keller, K.K. Nobuhara, Prosthetic patches for congenital diaphragmatic hernia repair: Surgisis vs Gore-Tex, J. Pediatr. Surg. 41 (2006) 29-33. https://doi.org/10.1016/j.jpedsurg.2005.10.005.

[126] R.H. Koehler, D. Begos, D. Berger, S. Carey, K. LeBlanc, A. Park, B. Ramshaw, R. Smoot, G. Voeller, Minimal adhesions to ePTFE mesh after laparoscopic ventral incisional hernia repair: reoperative findings in 65 cases., JSLS. 7 (2003) 335-340.

[127] T. Tollens, M. Den Hondt, K. Devroe, C. Terry, S. Speybroeck, C. Aelvoet, J.P. Vanrykel, Retrospective analysis of umbilical, epigastric, and small incisional hernia repair using the Ventralex ${ }^{\mathrm{TM}}$ hernia patch, Hernia. 15 (2011) 531-540. https://doi.org/10.1007/s10029-011-0816-y.

[128] K. Vychnevskaia, S. Mucci-Hennekinne, C. Casa, D. Brachet, K. Meunier, X. Briennon, A. Hamy, J.P. Arnaud, Intraperitoneal mesh repair of small ventral abdominal wall hernias with a Ventralex hernia patch, Dig. Surg. 27 (2010) 433-435. https://doi.org/10.1159/000318783.

[129] N. Schouten, T. van Dalen, N. Smakman, S.G. Elias, G.J. Clevers, E.J.M.M. Verleisdonk, P.H.P. Davids, I.P.J. Burgmans, The effect of ultrapro or prolene mesh on postoperative pain and well-being following endoscopic Totally Extraperitoneal (TEP) hernia repair (TULP): Study protocol for a randomized controlled trial, Trials. 13 (2012) 76. https://doi.org/10.1186/1745-6215-13-76.

[130] C. Schug-Paß, C. Tamme, F. Sommerer, A. Tannapfel, H. Lippert, F. Köckerling, A lightweight, partially absorbable mesh (Ultrapro) for endoscopic hernia repair: Experimental biocompatibility results obtained with a porcine model, Surg. Endosc. Other Interv. Tech. 22 (2008) 1100-1106. https://doi.org/10.1007/s00464-007-9585-1.

[131] P. Ambe, A. Meyer, L. Köhler, Repair of small and medium size ventral hernias with a Proceed Ventral Patch: A single center retrospective analysis, Surg. Today. 43 (2013) 381-385. https://doi.org/10.1007/s00595-012-0245-2.

[132] K. C. Sasse, C.L. Dionne, J. Brandt, Long-term durability and comfort of laparoscopic ventral hernia repair - PubMed, J. Soc. Laparosc. Vent. Hernia Repair. 16 (2012) 380-6. https://doi.org/10.4293/108680812X13462882736097.

[133] M.L. Baptista, M.E. Bonsack, J.P. Delaney, Seprafilm reduces adhesions to polypropylene mesh, Surgery. 128 (2000) 86-92. https://doi.org/10.1067/msy.2000.106810.

[134] R.C. Dinsmore, W.C. Calton, S.B. Harvey, M.W. Blaney, Prevention of adhesions to polypropylene mesh in a traumatized bowel model, J. Am. Coll. Surg. 191 (2000) 131-136. https://doi.org/10.1016/S1072-7515(00)00337-9.

[135] S. Gruber-Blum, N. Riepl, J. Brand, C. Keibl, H. Redl, R.H. Fortelny, A.H. Petter-Puchner, A comparison of Progrip®and Adhesix®self-adhering hernia meshes in an onlay model in the rat, Hernia. 18 (2014) 761-769. https://doi.org/10.1007/s10029-014-1258-0. 
[136] P. Batabyal, R.L. Haddad, J.S. Samra, S. Wickins, E. Sweeney, T.J. Hugh, Inguinal hernia repair with Parietex ProGrip mesh causes minimal discomfort and allows early return to normal activities, Am. J. Surg. 211 (2016) 24-30. https://doi.org/10.1016/j.amjsurg.2015.04.019.

[137] Y. Ramot, N. Kronfeld, M. Steiner, G. Klaiman, A. Hadid, M. Sudak, A. Nyska, Biodegradability and Safety Study of LifeMesh ${ }^{\mathrm{TM}}$, a Novel Self-adhesive Mesh, in Sprague-Dawley Rats, Toxicol. Pathol. 47 (2019) 483-493. https://doi.org/10.1177/0192623319833906.

[138] G. Jacobsen, C. DuCoin, Biodegradable meshes in abdominal wall surgery, in: Hernia Surg. Curr. Princ., Springer International Publishing, 2016: pp. 71-78. https://doi.org/10.1007/978-3-319-274706 6.

[139] E. Peeters, K.W.Y. Van Barneveld, M.H. Schreinemacher, G. De Hertogh, Y. Ozog, N. Bouvy, M. Miserez, One-year outcome of biological and synthetic bioabsorbable meshes for augmentation of large abdominal wall defects in a rabbit model, J. Surg. Res. 180 (2013) 274-283. https://doi.org/10.1016/j.jss.2013.01.025.

[140] J. Chamieh, W.H. Tan, R. Ramirez, E. Nohra, C. Apakama, W. Symons, Synthetic versus biologic mesh in single-stage repair of complex abdominal wall defects in a contaminated field, Surg. Infect. (Larchmt). 18 (2017) 112-118. https://doi.org/10.1089/sur.2016.106.

[141] W.S. Helton, P.M. Fisichella, R. Berger, S. Horgan, N.J. Espat, H. Abcarian, J. Landercasper, H.J. Debord, M. Dayton, J. Moore, L. Danto, Short-term outcomes with small intestinal submucosa for ventral abdominal hernia, Arch. Surg. 140 (2005) 549-562.

https://doi.org/10.1001/archsurg.140.6.549.

[142] E.I. Lee, C.J. Chike-Obi, P. Gonzalez, R. Garza, M. Leong, A. Subramanian, J. Bullocks, S.S. Awad, Abdominal wall repair using human acellular dermal matrix: a follow-up study, Am. J. Surg. 198 (2009) 650-657. https://doi.org/10.1016/j.amjsurg.2009.07.027.

[143] D.M. Hoganson, E.M. O’Doherty, G.E. Owens, D.O. Harilal, S.M. Goldman, C.M. Bowley, C.M. Neville, R.T. Kronengold, J.P. Vacanti, The retention of extracellular matrix proteins and angiogenic and mitogenic cytokines in a decellularized porcine dermis, Biomaterials. 31 (2010) 6730-6737. https://doi.org/10.1016/j.biomaterials.2010.05.019.

[144] N.J. Slater, M. Van Der Kolk, T. Hendriks, H. Van Goor, R.P. Bleichrodt, Biologic grafts for ventral hernia repair: A systematic review, Am. J. Surg. 205 (2013) 220-230. https://doi.org/10.1016/j.amjsurg.2012.05.028.

[145] F.S. Ayubi, P.J. Armstrong, M.S. Mattia, D.M. Parker, Abdominal wall hernia repair: A comparison of Permacol ${ }^{\circledR}$ and Surgisis ${ }^{\circledR}$ grafts in a rat hernia model, Hernia. 12 (2008) 373-378. https://doi.org/10.1007/s10029-008-0359-z.

[146] P.W. Hsu, C.J. Salgado, K. Kent, M. Finnegan, M. Pello, R. Simons, U. Atabek, B. Kann, Evaluation of porcine dermal collagen (Permacol) used in abdominal wall reconstruction, J. Plast. Reconstr. Aesthetic Surg. 62 (2009) 1484-1489. https://doi.org/10.1016/j.bjps.2008.04.060.

[147] D.S. Edelman, Laparoscopic herniorrhaphy with porcine small intestinal submucosa: a preliminary study., JSLS. 6 (2002) 203-205.

[148] B.K. Oelschlager, M. Barreca, L. Chang, C.A. Pellegrini, The use of small intestine submucosa in the repair of paraesophageal hernias: Initial observations of a new technique, Am. J. Surg. 186 (2003) 48. https://doi.org/10.1016/S0002-9610(03)00114-4.

[149] M. Rosen, J. Ponsky, R. Petras, A. Fanning, F. Brody, F. Duperier, Small intestinal submucosa as a bioscaffold for biliary tract regeneration, Surgery. 132 (2002) 480-486. https://doi.org/10.1067/msy.2002.126505.

[150] D.J. Schultz, K.J. Brasel, K.S. Spinelli, J. Rasmussen, J.A. Weigelt, Porcine small intestine submucosa as a treatment for enterocutaneous fistulas, J. Am. Coll. Surg. 194 (2002) 541-543. https://doi.org/10.1016/S1072-7515(02)01119-5.

[151] M.E. Franklin, J.J. Gonzalez, R.P. Michaelson, J.L. Glass, D.A. Chock, Preliminary experience with new bioactive prosthetic material for repair ofhernias in infected fields, Hernia. 6 (2002) 171-174. https://doi.org/10.1007/s10029-002-0078-9.

[152] M.E. Franklin, J.J. Gonzalez, J.L. Glass, Use of porcine small intestinal submucosa as a prosthetic device for laparoscopic repair of hernias in contaminated fields: 2-year follow-up, Hernia. 8 (2004) 186-189. https://doi.org/10.1007/s10029-004-0208-7.

[153] Á. Serrano-Aroca, C.D. Vera-Donoso, V. Moreno-Manzano, Bioengineering approaches for bladder 
regeneration, Int. J. Mol. Sci. 19 (2018) 1796. https://doi.org/10.3390/ijms19061796.

[154] E.F. Hirsch, Repair of an Abdominal Wall Defect after a Salvage Laparotomy for Sepsis, (2004) 324328. https://doi.org/10.1016/j.jamcollsurg.2003.09.016.

[155] B. Buinewicz, B. Rosen, Acellular Cadaveric Dermis ( AlloDerm ): A New Alternative for Abdominal Hernia Repair, 52 (2004) 188-194. https://doi.org/10.1097/01.sap.0000100895.41198.27.

[156] I.E. Geçim, S. Koçak, S. Ersoz, C. Bumin, D. Aribal, Recurrence after incisional hernia repair: Results and risk factors, Surg. Today. 26 (1996) 607-609. https://doi.org/10.1007/bf00311665.

[157] C.F. Bellows, A. Smith, J. Malsbury, W.S. Helton, Repair of incisional hernias with biological prosthesis: A systematic review of current evidence, Am. J. Surg. 205 (2013) 85-101. https://doi.org/10.1016/j.amjsurg.2012.02.019.

[158] A. Darehzereshki, M. Goldfarb, J. Zehetner, A. Moazzez, J.C. Lipham, R.J. Mason, N. Katkhouda, Biologic versus nonbiologic mesh in ventral hernia repair: A systematic review and meta-analysis, World J. Surg. 38 (2014) 40-50. https://doi.org/10.1007/s00268-013-2232-1.

[159] P. Giordano, R.D. Pullan, B. Ystgaard, F. Gossetti, M. Bradburn, A.J. McKinley, N.J. Smart, I.R. Daniels, The use of an acellular porcine dermal collagen implant in the repair of complex abdominal wall defects: a European multicentre retrospective study, Tech. Coloproctol. 19 (2015) 411-417. https://doi.org/10.1007/s10151-015-1307-4.

[160] M.M. Abdelfatah, N. Rostambeigi, E. Podgaetz, M.G. Sarr, Long-term outcomes (>5-year follow-up) with porcine acellular dermal matrix $\left(\right.$ Permacol $\left.^{\mathrm{TM}}\right)$ in incisional hernias at risk for infection, Hernia. 19 (2015) 135-140. https://doi.org/10.1007/s10029-013-1165-9.

[161] D. Russello, M. Sofia, P. Conti, S. Latteri, A. Pesce, F. Scaravilli, F. Vasta, G. Trombatore, V. Randazzo, E. Schembari, M. Barchitta, A. Agodi, G. La Greca, A retrospective, Italian multicenter study of complex abdominal wall defect repair with a Permacol biological mesh, Sci. Rep. 10 (2020) 3367. https://doi.org/10.1038/s41598-020-60019-0.

[162] H.C. Liang, Y. Chang, C.K. Hsu, M.H. Lee, H.W. Sung, Effects of crosslinking degree of an acellular biological tissue on its tissue regeneration pattern, Biomaterials. 25 (2004) 3541-3552. https://doi.org/10.1016/j.biomaterials.2003.09.109.

[163] N.J. Smart, N. Bryan, J.A. Hunt, I.R. Daniels, Porcine dermis implants in soft-tissue reconstruction: Current status, Biol. Targets Ther. 8 (2014) 83-90. https://doi.org/10.2147/BTT.S46469.

[164] M.L. Jarman-Smith, T. Bodamyali, C. Stevens, J.A. Howell, M. Horrocks, J.B. Chaudhuri, Porcine collagen crosslinking, degradation and its capability for fibroblast adhesion and proliferation, J. Mater. Sci. Mater. Med. 15 (2004) 925-932. https://doi.org/10.1023/B:JMSM.0000036281.47596.cc.

[165] G.S. De Silva, D.M. Krpata, Y. Gao, C.N. Criss, J.M. Anderson, H.T. Soltanian, M.J. Rosen, Y.W. Novitsky, Lack of identifiable biologic behavior in a series of porcine mesh explants, Surg. (United States). 156 (2014) 183-189. https://doi.org/10.1016/j.surg.2014.03.011.

[166] I.M. Mulder, E.B. Deerenberg, W.A. Bemelman, J. Jeekel, J.F. Lange, Infection susceptibility of crosslinked and non-crosslinked biological meshes in an experimental contaminated environment, in: Am. J. Surg., Elsevier Inc., 2015: pp. 159-166. https://doi.org/10.1016/j.amjsurg.2014.06.025.

[167] G.H. Altman, R.L. Horan, H.H. Lu, J. Moreau, I. Martin, J.C. Richmond, D.L. Kaplan, Silk matrix for tissue engineered anterior cruciate ligaments, Biomaterials. 23 (2002) 4131-4141. https://doi.org/10.1016/S0142-9612(02)00156-4.

[168] Q. Li, J. Wang, H. Liu, B. Xie, L. Wei, Tissue-engineered mesh for pelvic floor reconstruction fabricated from silk fibroin scaffold with adipose-derived mesenchymal stem cells, Cell Tissue Res. 354 (2013) 471-480. https://doi.org/10.1007/s00441-013-1719-2.

[169] R.L. Horan, D.S. Bramono, J.R.L. Stanley, Q. Simmons, J. Chen, H.E. Boepple, G.H. Altman, Biological and biomechanical assessment of a long-term bioresorbable silk-derived surgical mesh in an abdominal body wall defect model, Hernia. 13 (2009) 189-199. https://doi.org/10.1007/s10029008-0459-9.

[170] A.S. Gobin, C.E. Butler, A.B. Mathur, Defect Using Silk Fibroin-Chitosan Blend, Tissue Eng. 12 (2006).

[171] A.H. Teuschl, M. Van Griensven, H. Redl, Sericin removal from raw bombyx mori silk scaffolds of high hierarchical order, Tissue Eng. - Part C Methods. 20 (2014) 431-439.

https://doi.org/10.1089/ten.tec.2013.0278.

[172] M.W. Clemens, S. Downey, F. Agullo, M.R. Lehfeldt, G.M. Kind, H. Palladino, D. Marshall, M.L. 
Jewell, A.B. Mathur, B.P. Bengtson, M.W. Clemens, Clinical application of a silk fibroin protein biologic scaffold for abdominal wall fascial reinforcement, Plast. Reconstr. Surg. - Glob. Open. 2 (2014) 1-10. https://doi.org/10.1097/GOX.0000000000000217.

[173] J. Bueno-Lledó, M. Ceno, C. Pérez-Alonso, J. Martinez-Hoed, S. Pous-Serrano, Abdominal wall reconstruction with biosynthetic absorbable mesh after infected prosthesis explantation: single stage is better than two-stage approach of chronic mesh infection, Hernia. (2020). https://doi.org/10.1007/s10029-020-02309-0.

[174] J. Bueno-Lledó, M. Ceno, C. Perez-Alonso, J. Martinez-Hoed, A. Torregrosa-Gallud, S. PousSerrano, Biosynthetic Resorbable Prosthesis is Useful in Single-Stage Management of Chronic Mesh Infection After Abdominal Wall Hernia Repair, World J. Surg. 45 (2021) 443-450. https://doi.org/10.1007/s00268-020-05808-4.

[175] D. Charleux-Muller, R. Hurel, T. Fabacher, C. Brigand, S. Rohr, S. Manfredelli, G. Passot, P. OrtegaDeballon, V. Dubuisson, Y. Renard, B. Romain, Slowly absorbable mesh in contaminated incisional hernia repair: results of a French multicenter study, Hernia. (2021). https://doi.org/10.1007/s10029020-02366-5.

[176] A.L. Rivera-Briso, Á. Serrano-Aroca, Poly(3-Hydroxybutyrate-co-3-Hydroxyvalerate): Enhancement strategies for advanced applications, Polymers (Basel). 10 (2018) 732. https://doi.org/10.3390/polym10070732.

[177] A.L. Rivera-Briso, F.L. Aachmann, V. Moreno-Manzano, Á. Serrano-Aroca, Graphene Oxide Nanosheets versus Carbon Nanofibers: Enhancement of Physical and Biological Properties of Poly(3hydroxybutyrate-co-3-hydroxyvalerate) Films for Biomedical Applications, Int. J. Biol. Macromol. (2019) In press.

[178] W. Gong, T. Cheng, Q. Liu, Q. Xiao, J. Li, Surgical repair of abdominal wall defect with biomimetic nano/microfibrous hybrid scaffold, Mater. Sci. Eng. C. 93 (2018) 828-837. https://doi.org/10.1016/j.msec.2018.08.053.

[179] S.A.A.X. Michel, R.R.M. Vogels, N.D. Bouvy, M.L.W. Knetsch, N.M.S. Van Den Akker, M.J.J. Gijbels, C. Van Der Marel, J. Vermeersch, D.G.M. Molin, L.H. Koole, Utilization of flax fibers for biomedical applications, J. Biomed. Mater. Res. - Part B Appl. Biomater. 102 (2014) 477-487. https://doi.org/10.1002/jbm.b.33025.

[180] J. Warren, S.S. Desai, N.D. Boswell, B.H. Hancock, H. Abbad, J.A. Ewing, A.M. Carbonell, W.S. Cobb, Safety and Efficacy of Synthetic Mesh for Ventral Hernia Repair in a Contaminated Field, in: J. Am. Coll. Surg., Elsevier Inc., 2020: pp. 405-413. https://doi.org/10.1016/j.jamcollsurg.2019.12.008.

[181] M.T. Dayton, B.A. Buchele, S.S. Shirazi, L.B. Hunt, Use of an Absorbable Mesh to Repair Contaminated Abdominal-Wall Defects, Arch. Surg. 121 (1986) 954-960. https://doi.org/10.1001/archsurg.1986.01400080100019.

[182] A. Pans, P. Elen, W. Dewé, C. Desaive, Long-term results of polyglactin mesh for the prevention of incisional hernias in obese patients, World J. Surg. 22 (1998) 479-483. https://doi.org/10.1007/s002689900420.

[183] G. Pascual, S. Sotomayor, M. Rodríguez, B. Pérez-Köhler, J.M. Bellón, Repair of Abdominal Wall Defects with Biodegradable Laminar Prostheses: Polymeric or Biological?, PLoS One. 7 (2012). https://doi.org/10.1371/journal.pone.0052628.

[184] M.J. Rosen, J.J. Bauer, M. Harmaty, A.M. Carbonell, W.S. Cobb, B. Matthews, M.I. Goldblatt, D.J. Selzer, B.K. Poulose, B.M.E. Hansson, C. Rosman, J.J. Chao, G.R. Jacobsen, Multicenter, prospective, longitudinal study of the recurrence, surgical site infection, and quality of life after contaminated ventral hernia repair using biosynthetic absorbable mesh: The COBRA study, Ann. Surg. 265 (2017) 205-211. https://doi.org/10.1097/SLA.0000000000001601.

[185] M.Á. García-Ureña, J. López-Monclús, D. Cuccurullo, L.A. Blázquez Hernando, P. García-Pastor, S. Reggio, E. Jiménez Cubedo, C. San Miguel Méndez, A. Cruz Cidoncha, A. Robin Valle de Lersundi, Abdominal Wall Reconstruction Utilizing the Combination of Absorbable and Permanent Mesh in a Retromuscular Position: A Multicenter Prospective Study, World J. Surg. 43 (2019) 149-158. https://doi.org/10.1007/s00268-018-4765-9.

[186] C.E. Butler, F.A. Navarro, D.P. Orgill, Reduction of abdominal adhesions using composite collagengag implants for ventral hernia repair, J. Biomed. Mater. Res. 58 (2001) 75-80. https://doi.org/10.1002/1097-4636(2001)58:1<75::AID-JBM110>3.0.CO;2-J. 
[187] I. Felemovicius, M.E. Bonsack, G. Hagerman, J.P. Delaney, Prevention of adhesions to polypropylene mesh, J. Am. Coll. Surg. 198 (2004) 543-548. https://doi.org/10.1016/j.jamcollsurg.2003.12.004.

[188] A. Alponat, S.R. Lakshminarasappa, M. Teh, A. Rajnakova, S. Moochhala, P.M.Y. Goh, S.T.F. Chan, Effects of physical barriers in prevention of adhesions: An incisional hernia model in rats, J. Surg. Res. 68 (1997) 126-132. https://doi.org/10.1006/jsre.1996.4979.

[189] O. Langbach, S.H. Holmedal, O.J. Grandal, O. Røkke, Adhesions to Mesh after Ventral Hernia Mesh Repair Are Detected by MRI but Are Not a Cause of Long Term Chronic Abdominal Pain, Gastroenterol. Res. Pract. 2016 (2016). https://doi.org/10.1155/2016/2631598.

[190] X. Xia, X. Lu, X. Kang, J. Miao, K. Zhang, W. Guan, Two cases about mesh adhesion to intraabdominal cavity tissue after using mesh to repair an incisional hernia, Pakistan J. Med. Sci. 33 (2017) 1018-1021. https://doi.org/10.12669/pjms.334.12641.

[191] R.M. Young, R. Gustafson, R.C. Dinsmore, Sepramesh vs. Dualmesh for abdominal wall hernia repairs in a rabbit model, Curr. Surg. 61 (2004) 77-79. https://doi.org/10.1016/j.cursur.2003.09.011.

[192] J.M. Bellón, L.A. Contreras, J. Buján, Ultrastructural alterations of polytetrafluoroethylene prostheses implanted in abdominal wall provoked by infection: Clinical and experimental study, World J. Surg. 24 (2000) 528-532. https://doi.org/10.1007/s002689910085.

[193] J.M. Bellón, N. G-Honduvilla, F. Jurado, A. G-Carranza, J. Buján, In vitro interaction of bacteria with polypropylene/ePTFE prostheses, Biomaterials. 22 (2001) 2021-2024. https://doi.org/10.1016/S01429612(00)00390-2.

[194] G. Dieudonné, Plug repair of groin hernias: A 10-year experience, Hernia. 5 (2001) 189-191. https://doi.org/10.1007/s10029-001-0028-y.

[195] R.C. Read, Milestones in the history of hernia surgery: Prosthetic repair, Hernia. 8 (2004) 8-14. https://doi.org/10.1007/s10029-003-0169-2.

[196] Z. Sheikh, S. Najeeb, Z. Khurshid, V. Verma, H. Rashid, M. Glogauer, Biodegradable materials for bone repair and tissue engineering applications, Materials (Basel). 8 (2015) 5744-5794. https://doi.org/10.3390/ma8095273.

[197] S. Zhang, K. Xu, M.A. Darabi, Q. Yuan, M. Xing, Mussel-inspired alginate gel promoting the osteogenic differentiation of mesenchymal stem cells and anti-infection, Mater. Sci. Eng. C. 69 (2016) 496-504. https://doi.org/10.1016/j.msec.2016.06.044.

[198] M. Martí, B. Frígols, B. Salesa, Á. Serrano-Aroca, Calcium alginate/graphene oxide films: reinforced composites able to prevent Staphylococcus aureus and methicillin-resistant Staphylococcus epidermidis infections with no cytotoxicity for human keratinocyte HaCaT cells, Eur. Polym. J. 110 (2019) 14-21. https://doi.org/10.1016/J.EURPOLYMJ.2018.11.012.

[199] B. Salesa, M. Martí, B. Frígols, Á. Serrano-Aroca, Carbon nanofibers in pure form and in calcium alginate composites films: New cost-effective antibacterial biomaterials against the life-threatening multidrug-resistant Staphylococcus epidermidis, Polymers (Basel). 11 (2019). https://doi.org/10.3390/polym11030453.

[200] L. Elias, R. Taengua, B. Frígols, B. Salesa, Á. Serrano-Aroca, Carbon Nanomaterials and LED Irradiation as Antibacterial Strategies against Gram-Positive Multidrug-Resistant Pathogens, Int. J. Mol. Sci. 20 (2019) 3603. https://doi.org/10.3390/ijms20143603.

[201] C. Akyol, F. Kocaay, E. Orozakunov, V. Genc, I.K. Bayram, A. Cakmak, S. Baskan, E. Kuterdem, Outcome of the patients with chronic mesh infection following open inguinal hernia repair, J. Korean Surg. Soc. 84 (2013) 287-291. https://doi.org/10.4174/jkss.2013.84.5.287.

[202] M.N. Mavros, S. Athanasiou, V.G. Alexiou, P.K. Mitsikostas, G. Peppas, M.E. Falagas, Risk factors for mesh-related infections after hernia repair surgery: A meta-analysis of cohort studies, World J. Surg. 35 (2011) 2389-2398. https://doi.org/10.1007/s00268-011-1266-5.

[203] M. Mehrabi Bahar, A. Jabbari Nooghabi, M. Jabbari Nooghabi, A. Jangjoo, The role of prophylactic cefazolin in the prevention of infection after various types of abdominal wall hernia repair with mesh, Asian J. Surg. 38 (2015) 139-144. https://doi.org/10.1016/j.asjsur.2015.01.006.

[204] A. Ríos, J. Rodríguez, V. Munitiz, P. Alcaraz, P.D. Flores, P. Parrilla, Antibiotic prophylaxis in incisional hernia repair using a prosthesis, Hernia. 5 (2001) 148-152. https://doi.org/10.1007/s100290100026.

[205] S. Kathju, L. Nistico, R. Melton-Kreft, L.A. Lasko, P. Stoodley, Direct Demonstration of Bacterial Biofilms on Prosthetic Mesh after Ventral Herniorrhaphy, Surg. Infect. (Larchmt). 16 (2015) 45-53. 
https://doi.org/10.1089/sur.2014.026.

[206] S. Stremitzer, T. Bachleitner-Hofmann, B. Gradl, M. Gruenbeck, B. Bachleitner-Hofmann, M. Mittlboeck, M. Bergmann, Mesh graft infection following abdominal hernia repair: Risk factor evaluation and strategies of mesh graft preservation. A retrospective analysis of 476 operations, World J. Surg. 34 (2010) 1702-1709. https://doi.org/10.1007/s00268-010-0543-z.

[207] L. Chung, G.H. Tse, P.J. O'Dwyer, Outcome of patients with chronic mesh infection following abdominal wall hernia repair, Hernia. 18 (2014) 701-704. https://doi.org/10.1007/s 10029-014-1277-x.

[208] J.A. Trunzo, J.L. Ponsky, J. Jin, C.P. Williams, M.J. Rosen, A novel approach for salvaging infected prosthetic mesh after ventral hernia repair, Hernia. 13 (2009) 545-549.

https://doi.org/10.1007/s10029-009-0470-9.

[209] A.F. Engelsman, H.C. van der Mei, R.J. Ploeg, H.J. Busscher, The phenomenon of infection with abdominal wall reconstruction, Biomaterials. 28 (2007) 2314-2327. https://doi.org/10.1016/j.biomaterials.2007.01.028.

[210] A. Celdrán, J. Esteban, J. Mañas, J.J. Granizo, Wound infections due to Mycobacterium fortuitum after polypropylene mesh inguinal hernia repair, J. Hosp. Infect. 66 (2007) 374-377. https://doi.org/10.1016/j.jhin.2007.05.006.

[211] A. Luhmann, A. Moses, Successful conservative treatment of a candida albicans intraperitoneal mesh infection following laparoscopic ventral hernia repair, Hernia. 19 (2015) 845-847. https://doi.org/10.1007/s10029-013-1183-7.

[212] S.S. Holcomb, MRSA infections., Nursing (Lond). 38 (2008) 33. https://doi.org/10.1097/01.nurse.0000320354.17197.1f.

[213] A. Rampling, S. Wiseman, L. Davis, A.P. Hyett, A.N. Walbridge, G.C. Payne, A.J. Cornaby, Evidence that hospital hygiene is important in the control of methicillin-resistant Staphylococcus aureus, J. Hosp. Infect. 49 (2001) 109-116. https://doi.org/10.1053/jhin.2001.1013.

[214] R.O. Darouiche, V.G. Fowler, K. Adal, M. Kielhofner, D. Mansouri, L.B. Reller, Antimicrobial activity of prosthetic heart valve sewing cuffs coated with minocycline and rifampin, Antimicrob. Agents Chemother. 46 (2002) 543-545. https://doi.org/10.1128/AAC.46.2.543-545.2002.

[215] M. Martí, A. Tuñón-Molina, F.L. Aachmann, Y. Muramoto, T. Noda, K. Takayama, Á. SerranoAroca, Protective Face Mask Filter Capable of Inactivating SARS-CoV-2, and Methicillin-Resistant Staphylococcus aureus and Staphylococcus epidermidis, Polymers (Basel). 13 (2021) 207. https://doi.org/10.3390/polym13020207.

[216] C. Labay, J.M. Canal, M. Modic, U. Cvelbar, M. Quiles, M. Armengol, M.A. Arbos, F.J. Gil, C. Canal, Antibiotic-loaded polypropylene surgical meshes with suitable biological behaviour by plasma functionalization and polymerization, Biomaterials. 71 (2015) 132-144. https://doi.org/10.1016/j.biomaterials.2015.08.023.

[217] O. Goëau-Brissonnière, V. Leflon, M. Letort, M.H. Nicolas, Resistance of antibiotic-bonded gelatincoated polymer meshes to Staphylococcus aureus in a rabbit subcutaneous pouch model, Biomaterials. 20 (1999) 229-232. https://doi.org/10.1016/S0142-9612(98)00164-1.

[218] E.E. Sadava, D.M. Krpata, Y. Gao, Y.W. Novitsky, M.J. Rosen, Does Presoaking Synthetic Mesh in Antibiotic Solution Reduce Mesh Infections? An Experimental Study, J. Gastrointest. Surg. 17 (2013) 562-568. https://doi.org/10.1007/s11605-012-2099-8.

[219] A. Wiegering, B. Sinha, L. Spor, U. Klinge, U. Steger, C.T. Germer, U.A. Dietz, Gentamicin for prevention of intraoperative mesh contamination: demonstration of high bactericide effect (in vitro) and low systemic bioavailability (in vivo), Hernia. 18 (2014) 691-700. https://doi.org/10.1007/s10029-014-1293-x.

[220] J.M. Suárez-Grau, S. Morales-Conde, V. González Galán, J.A. Martín Cartes, F. Docobo Durantez, F.J. Padillo Ruiz, Antibiotic embedded absorbable prosthesis for prevention of surgical mesh infection: experimental study in rats, Hernia. 19 (2015) 187-194. https://doi.org/10.1007/s10029-0141334-5.

[221] B. Pérez-Köhler, F. García-Moreno, T. Brune, G. Pascual, J.M. Bellón, Preclinical bioassay of a polypropylene mesh for hernia repair pretreated with antibacterial solutions of chlorhexidine and allicin: An in vivo study, PLoS One. 10 (2015) 1-17. https://doi.org/10.1371/journal.pone.0142768.

[222] R. Satishkumar, S. Sankar, Y. Yurko, A. Lincourt, J. Shipp, B.T. Heniford, A. Vertegel, Evaluation of the antimicrobial activity of lysostaphin-coated hernia repair meshes, Antimicrob. Agents Chemother. 
55 (2011) 4379-4385. https://doi.org/10.1128/AAC.01056-10.

[223] Y. Yurko, K. McDeavitt, R.S. Kumar, T. Martin, A. Prabhu, A.E. Lincourt, A. Vertegel, B.T. Heniford, Antibacterial mesh: A novel technique involving naturally occurring cellular proteins, Surg. Innov. 19 (2012) 20-26. https://doi.org/10.1177/1553350611410716.

[224] P. Avetta, R. Nisticò, M.G. Faga, D. D’Angelo, E.A. Boot, R. Lamberti, S. Martorana, P. Calza, D. Fabbri, G. Magnacca, Hernia-repair prosthetic devices functionalised with chitosan and ciprofloxacin coating: Controlled release and antibacterial activity, J. Mater. Chem. B. 2 (2014) 5287-5294. https://doi.org/10.1039/c4tb00236a.

[225] V. Kumar, C. Jolivalt, J. Pulpytel, R. Jafari, F. Arefi-Khonsari, Development of silver nanoparticle loaded antibacterial polymer mesh using plasma polymerization process, J. Biomed. Mater. Res. - Part A. 101 A (2013) 1121-1132. https://doi.org/10.1002/jbm.a.34419.

[226] Á. Serrano-Aroca, M. Monleón-Pradas, J.L. Gómez-Ribelles, Plasma-induced polymerisation of hydrophilic coatings onto macroporous hydrophobic scaffolds, Polymer (Guildf). 48 (2007) 20712078.

[227] A. Serrano Aroca, J.L. Gómez Ribelles, M. Monleón Pradas, A. Vidaurre Garayo, J. Suay Antón, Characterisation of macroporous poly(methyl methacrylate) coated with plasma-polymerised poly(2hydroxyethyl acrylate), Eur. Polym. J. 43 (2007) 4552-4564. https://doi.org/10.1016/j.eurpolymj.2007.07.026.

[228] K. Junge, U. Klinge, R. Rosch, P. Lynen, M. Binnebösel, J. Conze, P.R. Mertens, R. Schwab, V. Schumpelick, Improved collagen type I/III ratio at the interface of gentamicin- supplemented polyvinylidenfluoride mesh materials, Langenbeck's Arch. Surg. 392 (2007) 465-471. https://doi.org/10.1007/s00423-006-0138-1.

[229] K. Junge, R. Rosch, U. Klinge, C. Krones, B. Klosterhalfen, P.R. Mertens, P. Lynen, D. Kunz, A. Preiß, H. Peltroche-Llacsahuanga, V. Schumpelick, Gentamicin supplementation of polyvinylidenfluoride mesh materials for infection prophylaxis, Biomaterials. 26 (2005) 787-793. https://doi.org/10.1016/j.biomaterials.2004.02.070.

[230] B.C. Gross, J.L. Erkal, S.Y. Lockwood, C. Chen, D.M. Spence, Evaluation of 3D printing and its potential impact on biotechnology and the chemical sciences, Anal. Chem. 86 (2014) 3240-3253. https://doi.org/10.1021/ac403397r.

[231] BBRAUN, Optilene® Silver Mesh LP \&amp; Elastic, (n.d.). https://www.bbraun.de/de/products/b219/optilene-silver-meshlpelastic.html (accessed February 7, 2021).

[232] M.V.D.Z. Park, A.M. Neigh, J.P. Vermeulen, L.J.J. de la Fonteyne, H.W. Verharen, J.J. Briedé, H. van Loveren, W.H. de Jong, The effect of particle size on the cytotoxicity, inflammation, developmental toxicity and genotoxicity of silver nanoparticles, Biomaterials. 32 (2011) 9810-9817. https://doi.org/10.1016/j.biomaterials.2011.08.085.

[233] J. Du, J. Tang, S. Xu, J. Ge, Y. Dong, H. Li, M. Jin, A review on silver nanoparticles-induced ecotoxicity and the underlying toxicity mechanisms, Regul. Toxicol. Pharmacol. 98 (2018) 231-239. https://doi.org/10.1016/j.yrtph.2018.08.003.

[234] C. Gunawan, C.P. Marquis, R. Amal, G.A. Sotiriou, S.A. Rice, E.J. Harry, Widespread and Indiscriminate Nanosilver Use: Genuine Potential for Microbial Resistance, ACS Nano. 11 (2017) 3438-3445. https://doi.org/10.1021/acsnano.7b01166.

[235] S.L. Percival, P.G. Bowler, D. Russell, Bacterial resistance to silver in wound care, J. Hosp. Infect. 60 (2005) 1-7. https://doi.org/10.1016/j.jhin.2004.11.014.

[236] K.C. Harth, M.J. Rosen, T.R. Thatiparti, M.R. Jacobs, I. Halaweish, S. Bajaksouzian, J. Furlan, H.A. Von Recum, Antibiotic-releasing mesh coating to reduce prosthetic sepsis: An in vivo study, J. Surg. Res. 163 (2010) 337-343. https://doi.org/10.1016/j.jss.2010.03.065.

[237] A. Majumder, J.R. Scott, Y.W. Novitsky, Evaluation of the antimicrobial efficacy of a novel Rifampin/minocycline-coated, noncrosslinked porcine acellular dermal matrix compared with uncoated scaffolds for soft tissue repair, Surg. Innov. 23 (2016) 442-455. https://doi.org/10.1177/1553350616656280.

[238] J.A. Blatnik, T.R. Thatiparti, D.M. Krpata, S.T. Zuckerman, M.J. Rosen, H.A. von Recum, Infection prevention using affinity polymer-coated, synthetic meshes in a pig hernia model, J. Surg. Res. 219 (2017) 5-10. https://doi.org/10.1016/j.jss.2017.05.003. 
[239] G. Vermet, S. Degoutin, F. Chai, M. Maton, C. Flores, C. Neut, P.E. Danjou, B. Martel, N. Blanchemain, Cyclodextrin modified PLLA parietal reinforcement implant with prolonged antibacterial activity, Acta Biomater. 53 (2017) 222-232. https://doi.org/10.1016/j.actbio.2017.02.017.

[240] J. Reinbold, T. Hierlemann, L. Urich, A.K. Uhde, I. Müller, T. Weindl, U. Vogel, C. Schlensak, H.P. Wendel, S. Krajewski, Biodegradable rifampicin-releasing coating of surgical meshes for the prevention of bacterial infections, Drug Des. Devel. Ther. 11 (2017) 2753-2762. https://doi.org/10.2147/DDDT.S138510.

[241] N. Sanbhal, X. Saitaer, Y. Li, Y. Mao, T. Zou, G. Sun, L. Wang, Controlled levofloxacin release and antibacterial properties of $\beta$-cyclodextrins-grafted polypropylene mesh devices for hernia repair, Polymers (Basel). 10 (2018). https://doi.org/10.3390/polym10050493.

[242] H. Han, J. Zhu, F.F. Zhang, F.X. Li, X.L. Wang, J.Y. Yu, X.H. Qin, D.Q. Wu, Hydrophilic and degradable polyesters based on 1-aspartic acid with antibacterial properties for potential application in hernia repair, Biomater. Sci. 7 (2019) 5404-5413. https://doi.org/10.1039/c9bm01214a.

[243] B. Pérez-Köhler, F. Linardi, G. Pascual, J.M. Bellón, D. Eglin, O. Guillaume, Efficacy of antimicrobial agents delivered to hernia meshes using an adaptable thermo-responsive hyaluronic acid-based coating, Hernia. (2019). https://doi.org/10.1007/s10029-019-02096-3.

[244] G. Muzio, S. Perero, M. Miola, M. Oraldi, S. Ferraris, E. Vernè, F. Festa, R.A. Canuto, V. Festa, M. Ferraris, Biocompatibility versus peritoneal mesothelial cells of polypropylene prostheses for hernia repair, coated with a thin silica/silver layer, J. Biomed. Mater. Res. - Part B Appl. Biomater. 105 (2017) 1586-1593. https://doi.org/10.1002/jbm.b.33697.

[245] Y. Yurtkap, A.P. Jairam, R. Kaufmann, L.F. Kroese, M.C. Clahsen-van Groningen, J.W. Mouton, A.G. Menon, G.J. Kleinrensink, J. Jeekel, J.F. Lange, E.J. Belt, Zinc-Impregnated Mesh for Abdominal Wall Repair Reduces Infection in a Rat Model of Peritonitis, J. Surg. Res. 246 (2020) 560-567. https://doi.org/10.1016/j.jss.2019.09.046.

[246] A.S. Gobin, C.E. Butler, A.B. Mathur, Repair and regeneration of the abdominal wall musculofascial defect using silk fibroin-chitosan blend, Tissue Eng. 12 (2006) 3383-3394. https://doi.org/10.1089/ten.2006.12.3383.

[247] J. Qiao, Z. Jiang, Y. Yang, J. Chi, X. Qiao, B. Han, W. Liu, Study of a new biodegradable hernia patch to repair abdominal wall defect in rats, Carbohydr. Polym. 172 (2017) 255-264. https://doi.org/10.1016/j.carbpol.2017.05.035.

[248] J. Qiao, Z. Jiang, X. Liang, Y. Yang, W. Liu, B. Han, Biomechanical properties and healing effects of chitin patch in a rat full-thickness abdominal wall defect model, J. Biomed. Mater. Res. - Part B Appl. Biomater. 106 (2018) 1349-1357. https://doi.org/10.1002/jbm.b.33939.

[249] B. Pérez-Köhler, F. García-Moreno, Y. Bayon, G. Pascual, J.M. Bellón, Inhibition of Staphylococcus aureus adhesion to the surface of a reticular heavyweight polypropylene mesh soaked in a combination of chlorhexidine and allicin: An in vitro study, PLoS One. 10 (2015) 1-19. https://doi.org/10.1371/journal.pone.0126711.

[250] B. Pérez-Köhler, M. Fernández-Gutiérrez, G. Pascual, F. García-Moreno, J. San Román, J.M. Bellón, In vitro assessment of an antibacterial quaternary ammonium-based polymer loaded with chlorhexidine for the coating of polypropylene prosthetic meshes, Hernia. 20 (2016) 869-878. https://doi.org/10.1007/s10029-016-1537-z.

[251] N. Sanbhal, Y. Mao, G. Sun, Y. Li, M. Peerzada, L. Wang, Preparation and characterization of antibacterial polypropylene meshes with covalently incorporated $\beta$-cyclodextrins and captured antimicrobial agent for hernia repair, Polymers (Basel). 10 (2018). https://doi.org/10.3390/polym10010058.

[252] B. Pérez-Köhler, S. Benito-Martínez, M. Rodríguez, F. García-Moreno, G. Pascual, J.M. Bellón, Experimental study on the use of a chlorhexidine-loaded carboxymethylcellulose gel as antibacterial coating for hernia repair meshes, Hernia. 23 (2019) 789-800. https://doi.org/10.1007/s10029-01901917-9.

[253] P. Liu, K. Fu, X. Zeng, N. Chen, X. Wen, Fabrication and Characterization of Composite Meshes Loaded with Antimicrobial Peptides, ACS Appl. Mater. Interfaces. 11 (2019) 24609-24617. https://doi.org/10.1021/acsami.9b07246.

[254] P. Liu, N. Chen, J. Jiang, X. Wen, Preparation and in vitro evaluation of new composite mesh 
functionalized with cationic antimicrobial peptide, Materials (Basel). 12 (2019). https://doi.org/10.3390/MA12101676.

[255] A. Çakmak, Y. Çirpanli, E. Bilensoy, K. Yorganci, S. Çaliş, Z. Saribaş, V. Kaynaroğlu, Antibacterial activity of triclosan chitosan coated graft on hernia graft infection model, Int. J. Pharm. 381 (2009) 214-219. https://doi.org/10.1016/j.ijpharm.2009.05.059.

[256] Z. Song, Y. Ma, G. Xia, Y. Wang, W. Kapadia, Z. Sun, W. Wu, H. Gu, W. Cui, X. Huang, In vitro and in vivo combined antibacterial effect of levofloxacin/silver co-loaded electrospun fibrous membranes, 2017. https://doi.org/10.1039/c7tb01243h.

[257] I.J. Hall Barrientos, E. Paladino, S. Brozio, M.K. Passarelli, S. Moug, R.A. Black, C.G. Wilson, D.A. Lamprou, Fabrication and characterisation of drug-loaded electrospun polymeric nanofibers for controlled release in hernia repair, Int. J. Pharm. 517 (2017) 329-337. https://doi.org/10.1016/j.ijpharm.2016.12.022.

[258] F.J. Calero Castro, Y. Yuste, S. Pereira, M.D. Garvín, M.Á. López García, F.J. Padillo, F. de la Portilla, Proof of concept, design, and manufacture via 3-D printing of a mesh with bactericidal capacity: Behaviour in vitro and in vivo, J. Tissue Eng. Regen. Med. 13 (2019) 1955-1964. https://doi.org/10.1002/term.2944.

[259] M.M. Shokry, I.A. Khalil, A. El-Kasapy, A. Osman, A. Mostafa, M. Salah, I.M. El-Sherbiny, Multifunctional prosthetic polyester-based hybrid mesh for repairing of abdominal wall hernias and defects, Carbohydr. Polym. 223 (2019) 115027. https://doi.org/10.1016/j.carbpol.2019.115027.

[260] A. Keirouz, N. Radacsi, Q. Ren, A. Dommann, G. Beldi, K. Maniura-Weber, R.M. Rossi, G. Fortunato, Nylon-6/chitosan core/shell antimicrobial nanofibers for the prevention of mesh-associated surgical site infection, J. Nanobiotechnology. 18 (2020) 1-17. https://doi.org/10.1186/s12951-02000602-9.

[261] B. Pérez-Köhler, S. Benito-Martínez, F. García-Moreno, M. Rodríguez, G. Pascual, J.M. Bellón, Antibacterial polypropylene mesh fixation with a cyanoacrylate adhesive improves its response to infection, Surgery. (2021). https://doi.org/10.1016/j.surg.2021.01.012.

[262] J.L. Aparicio-Collado, J.J. Novoa, J. Molina-Mateo, C. Torregrosa-Cabanilles, Á. Serrano-Aroca, R. Sabater i Serra, Novel Semi-Interpenetrated Polymer Networks of Poly(3-Hydroxybutyrate-co-3Hydroxyvalerate)/Poly (Vinyl Alcohol) with Incorporated Conductive Polypyrrole Nanoparticles, Polymers (Basel). 13 (2020) 57. https://doi.org/10.3390/polym13010057.

[263] M. Martí, B. Frígols, Á. Serrano-Aroca, Antimicrobial Characterization of Advanced Materials for Bioengineering Applications, J. Vis. Exp. (2018) e57710. https://doi.org/10.3791/57710.

[264] B. Frígols, M. Martí, B. Salesa, C. Hernández-Oliver, O. Aarstad, A.-S.T. Ulset, G.I. Sætrom, F.L. Aachmann, Á. Serrano-Aroca, Graphene oxide in zinc alginate films: Antibacterial activity, cytotoxicity, zinc release, water sorption/diffusion, wettability and opacity, PLoS One. 14 (2019). https://doi.org/10.1371/journal.pone.0212819.

[265] M. Llorens-Gámez, B. Salesa, Á. Serrano-Aroca, Physical and biological properties of alginate/carbon nanofibers hydrogel films, Int. J. Biol. Macromol. 151 (2020) 499-507. https://doi.org/10.1016/j.ijbiomac.2020.02.213.

[266] B. Salesa, M. Llorens-Gámez, Á. Serrano-Aroca, Study of 1D and 2D carbon nanomaterial in alginate films, Nanomaterials. 10 (2020) 206. https://doi.org/10.3390/nano10020206.

[267] R. Sabater i Serra, J. Molina-Mateo, C. Torregrosa-Cabanilles, A. Andrio-Balado, J.M.M. Dueñas, Á. Serrano-Aroca, Bio-Nanocomposite hydrogel based on zinc alginate/graphene oxide: Morphology, structural conformation, thermal behavior/degradation, and dielectric properties, Polymers (Basel). 12 (2020) 702. https://doi.org/10.3390/polym12030702.

[268] M. Llorens-Gámez, Á. Serrano-Aroca, Low-Cost Advanced Hydrogels of Calcium Alginate/Carbon Nanofibers with Enhanced Water Diffusion and Compression Properties, Polymers (Basel). 10 (2018) 405. https://doi.org/10.3390/polym10040405.

[269] Á. Serrano-Aroca, S. Deb, Synthesis of irregular graphene oxide tubes using green chemistry and their potential use as reinforcement materials for biomedical applications, PLoS One. 12 (2017) e0185235. https://doi.org/10.1371/journal.pone.0185235.

[270] I. Sanmartín-Santos, S. Gandía-Llop, Á. Serrano-Aroca, First report of antiviral activity of carbon nanofibers: Enhancement of the viral inhibition capacity of calcium alginate films, BioRxiv. (2020) 2020.08.18.255646. https://doi.org/10.1101/2020.08.18.255646. 
[271] I.L. Romero, J.B.N.S. Malta, C.B. Silva, L.M.J. Mimica, K.H. Soong, R.Y. Hida, Antibacterial properties of cyanoacrylate tissue adhesive: Does the polymerization reaction play a role, Indian J. Ophthalmol. 57 (2009) 341-344. https://doi.org/10.4103/0301-4738.55065. 